\title{
Application of Equilibrium Optimizer Algorithm for Optimal Power Flow with High Penetration of Renewable Energy
}

\author{
Khaled Nusair ${ }^{1, *(1)}$ and Lina Alhmoud ${ }^{2}$ (D) \\ 1 Protection and Metering Department, National Electric Power Company, Amman 11181, Jordan \\ 2 Department of Power Engineering, Hijjawi Faculty for Engineering Technology, Yarmouk University, \\ Irbid 21163, Jordan; lina.hmoud@yu.edu.jo \\ * Correspondence: khalednusair2016@yahoo.com
}

Received: 18 October 2020; Accepted: 15 November 2020; Published: 19 November 2020

\begin{abstract}
In recent decades, the energy market around the world has been reshaped to accommodate the high penetration of renewable energy resources. Although renewable energy sources have brought various benefits, including low operation cost of wind and solar PV power plants, and reducing the environmental risks associated with the conventional power resources, they have imposed a wide range of difficulties in power system planning and operation. Naturally, classical optimal power flow $(\mathrm{OPF})$ is a nonlinear problem. Integrating renewable energy resources with conventional thermal power generators escalates the difficulty of the OPF problem due to the uncertain and intermittent nature of these resources. To address the complexity associated with the process of the integration of renewable energy resources into the classical electric power systems, two probability distribution functions (Weibull and lognormal) are used to forecast the voltaic power output of wind and solar photovoltaic, respectively. Optimal power flow, including renewable energy, is formulated as a single-objective and multi-objective problem in which many objective functions are considered, such as minimizing the fuel cost, emission, real power loss, and voltage deviation. Real power generation, bus voltage, load tap changers ratios, and shunt compensators values are optimized under various power systems' constraints. This paper aims to solve the OPF problem and examines the effect of renewable energy resources on the above-mentioned objective functions. A combined model of wind integrated IEEE 30-bus system, solar PV integrated IEEE 30-bus system, and hybrid wind and solar PV integrated IEEE 30-bus system is performed using the equilibrium optimizer technique (EO) and other five heuristic search methods. A comparison of simulation and statistical results of EO with other optimization techniques showed that $\mathrm{EO}$ is more effective and superior and provides the lowest optimization value in term of electric power generation, real power loss, emission index and voltage deviation.
\end{abstract}

Keywords: active power loss; generation cost; emission index; optimal power flow; equilibrium optimizer algorithim; solar PV and wind system; hybrid energy system

\section{Introduction}

\subsection{Background}

The urgent need for reducing the fuel cost of the conventional power generation units and minimizing the greenhouse gases emitted from the thermal power generators have led various electric power companies to go toward utilizing renewable energy resources. Furthermore, the advanced technologies of renewable energy resources have contributed significantly to them becoming the most 
inexpensive and environmentally friendly resources. Integrating wind and solar PV in proper locations and appropriate settings of the variables of the conventional power networks may have a significant impact on the performance of power system control and operation.

To make the modeling of wind and solar PV more accurate and realistic, the Weibull probability distribution function was used to forecast the wind speed [1,2], whereas lognormal probability distribution function was used to mimic the intermittent nature of solar irradiance in $[3,4]$.

\subsection{Literature Review}

Numerous publications in the literature studied the optimal power flow (OPF) problem for systems consisting of conventional power generation and renewable energy power plants. Deterministic, stochastic or hybrid optimization methods are used extensively to address the issues associated with increased penetration of non-dispatchable renewable energy, advanced controls such as FACTS devices and deregulated electricity markets.

Various conventional optimization techniques are used to solve the OPF problem. For instance, continuous nonlinear programming (NLP) was proposed [5]. The main advantage of NLP is that it is easily applied for solving large-scale power systems but it does not consider all of the system components. An extended conic quadratic format [6] is presented to solve the economic dispatch and decrease real power loss. Besides, the predictor-corrector interior point algorithm (PCIP) is proposed to fit the OPF for solving nonlinear programming problems [7]. Quadratic programming (QP) is used to derive a loss formula based on the incremental power flow. QP's main advantages are that it does not require the calculation of the gradient steps, it is more accurate than linear and non-linear programming, and QB is also applicable in ill-conditions problem [8]. Sequential quadratic programming (SQP) is used to address large scale OPF; it also depends on transforming the original problem to a sequence of a linearly constrained sub-problem by applying an augmented Lagrangian [9]. Mixed integer linear programming (MILP) are adapted to minimize transmission losses and reactive generator outputs. MILP can provide the most accurate way to represent power system with a discrete control parameter. However, the main drawback of MILP is the presence of a strong trade-off between the accuracy of the system and the tractability of the problem [10]. Although these methods have excellent convergence characteristics, they have various drawbacks, including failing to find the global solution because of non-convexity and facing difficulty while handling the problems with non-differentiable and discontinuous objective functions.

Recently, metaheuristic optimization algorithms have been gaining much attention due to flexibility, free of derivation, and local optima avoidance. Thus, single and multi-objective optimization methods overcome the shortcomings attributed to classical techniques. A gravitational search algorithm (GSA) to find the optimal solution for OPF and IEEE 30-bus and 57-bus systems are examined. One of the most significant merits of GSA is the gravitational constant which has the ability to adjust the accuracy of the search to speed up the solution process. Another advantage, GSA is a memory-less method but it can work effectively similarly to algorithms with memory [11]. The basic fuel cost, voltage profile, voltage stability, and non-smooth quadratic cost are minimized and optimized using a differential evolution algorithm (DE). This approach has various benefits, including simple encoding, integer discrete handling, fast convergence and optimal solution identification [12]. The black hole-based optimization method is used to address the OPF problem for IEEE 30-bus and Algerian 59-bus power systems; simplicity and the parameter-free aspect are the main two benefits of this method over well-known optimization techniques [13]. Constrained OPF problem for IEEE 30-bus, 57-bus, and 118-bus is optimized using a moth swarm algorithm [14]. A multi-objective OPF to minimize the generation cost and environmental pollution using a fuzzy membership function to choose a compromise solution from the Pareto optimal solutions is discussed [15]. The fuel cost, voltage deviation, and real power loss are minimized as a multi-objective OPF problem using a gravitational search algorithm [16]. A modified teaching learning-based optimization algorithm (MTLBO) added a self-adapting wavelet mutation strategy and a fuzzy clustering. MTLBO provides a self-adaptive wavelet to improve the search 
capability, diversity and convergence speed. Moreover, a fuzzy decision making method is applied to sort the solution according to their significance. Finally, a smart population selection is included to select the population of the next iterations of the algorithms [17]. A hybrid of fuzzy evolutionary and swarm optimization is proposed to minimize the cost of active power generation and real power losses [18].

A fuzzy-based modified bee colony (MABC) is presented to solve discrete OPF using multi-objective mixed integer nonlinear. Furthermore, it is proven that MABC is more effective in finding the global search exploration than original bee colony and it also does not degrade while solving the higher dimension power systems [19]. Emission, real power losses, and voltage deviation are all minimized as a multi-objective OPF using a multi-objective modified imperialist competitive algorithm. This new technique is strong, effective and fast in comparison with the original imperialist competitive algorithm [20]. The particle swarm optimization and the shuffled frog leaping algorithm are hybridized to solve OPF using the generator's constraints, such as prohibited zones and valve point effect.This method can successfully increase the diversity of generating population by adding four dominant strategies to move each individual of the existing swarm [21]. A chaotic invasive weed optimization algorithm is proposed to solve the OPF problem with non-smooth and non-convex fuel cost curves. The difficulties that the original invasive weed optimization algorithm faces in order to reach a better optimal solution were addressed. Additionally, this method is more stable and suitable for non-linear OPF [22]. Brain storming optimization (BSO) and teaching-learning optimization(TLBO) are hybridized to minimize the fuel cost of thermal generation units; this method outperforms TLBO and BSO, owing to a self evolving principle which is applied to the control parameter and a higher memory capability during its intermediate stages [23]. A hybrid optimization algorithm is based on sequential quadratic programming (SQP) to generate an initial population. Then, a differential evolution(DE) took that population to find the optimal solution more effectively and it was used to minimize the fuel cost with valve point and the transmission line real losses, the unfavorable results of DE which include stagnation and premature convergence can be avoided through benefiting from the impressive role of SQP in relaxing the discrete variables of the system [24].

A growing and considerable effort have been made in recent years to solve and model the OPF problem, including renewable energy sources. The OPF problem with taking into account uncertainties in the wind, solar, and load forecast and optimized using a genetic algorithm and two-point estimate method is presented in [25]. A hybrid method called moth swarm algorithm and gravitational search algorithm is used to solve the problem of OPF, including wind power [26]. A modified two-point estimation method is used to solve probabilistic OPF incorporating wind and solar photovoltaic power [27]. Hybrid wind photovoltaic power systems are optimized using the unscented transformation method, which can carry out probabilistic OPF with high accuracy and less computational time [28]. The OPF, including wind, is optimized using a fuzzy-based particle swarm optimization. A fuzzy set modeled the forecast load demand and wind speed [29].

Besides, OPF incorporating wind power energy is optimized by a hybrid algorithm called a hybrid dragonfly with aging particle swarm optimization [30]. Adaptive differential evolution with proper constraint handling method is addressed OPF, including wind and solar. The forecast wind and solar photovoltaic are modeled using Weibull and lognormal probability distribution functions [4]. An optimal reactive power dispatch with solar photovoltaic power and its impact on minimizing real power losses is addressed using the Jaya algorithm to solve this issue [31]. A constrained multi-objective population external optimization method in [32] is presented to minimize the fuel cost and emission in the presence of renewable energy sources. A grey wolf optimization algorithm (GWO) in [33] was proposed to tune the parameters of a thyristor controlled series compensator and address OPF, including wind and solar power. A best guided artificial bee colony optimization in [1] was to find the optimal setting of conventional and renewable power generation. 


\subsection{Contribution and Paper Organization}

In the present work, an equilibrium optimizer [34], which is a novel optimization method inspired by controlling the volume mass balance model for estimating both equilibrium and dynamic states, is used to prove its performance in solving the OPF problem. It is implemented on (i) IEEE 30-bus system, (ii) wind integrated IEEE 30-bus system, (iii) solar PV integrated IEEE 30-bus system, and (iv) hybrid wind and solar PV integrated IEEE 30-bus system. Real power loss minimizations, total cost minimization of generating units and emission index minimization are considered to be the objective functions of the OPF problem. Weibull and lognormal probability distribution functions are used to model the wind speed and solar irradiance to forecast the output power of wind and solar PV systems. Furthermore, aiming to fill the gap in the literature, this paper investigates the impact of the presence of only wind or only solar PV or both of them on enhancing the objective functions of the OPF problem. In addition, a comprehensive statistical analysis for the equilibrium optimizer technique (EO) and other optimization techniques are used.

The rest of this paper is organized as follows: the formulation of OPF problem is described in Section 2. Then, a mathematical model of wind and solar PV plants is introduced in Section 3. Section 4 presents the equilibrium optimizer technique (EO) and its implementation to solve the OPF problem. Section 5 presents the test systems and the input parameters of the test systems and the optimization methods. Simulation results are explained in Section 6. Finally, Section 7 draws the conclusion of this work.

\section{Problem Formulation of OPF}

\subsection{General Structure of $O P F$}

Generally, OPF aims to minimizes some objective functions. $f_{0}$ is the objective function to be minimized, and $h$ and $g$ are the equality and inequality constraints in the power system network; OPF can be expressed as [14,35]:

$$
\begin{array}{ll}
\text { Minimize } & f_{o}(\boldsymbol{x}, \boldsymbol{u}) \\
\text { subject to } & g(\boldsymbol{x}, \boldsymbol{u}) \leq 0 \\
& h(\boldsymbol{x}, \boldsymbol{u})=0
\end{array}
$$

$x$ is a state vector of dependent variables including the real power of swing generator $\left(P_{G_{1}}\right)$, $\left(V_{L_{i}}\right)$ is the voltage magnitude of load buses, $\left(Q_{G_{i}}\right)$ is the reactive power of generator at $i_{\text {th }}$ bus and $\left(S_{l_{i}}\right)$ is the loading of the $i_{t h}$ transmission line. $x$ can be expressed as follows [14,35]:

$$
x=\left[P_{G_{1}}, V_{L_{1}}, \ldots, V_{L_{n p q}}, Q_{G 1}, \ldots, Q_{G_{N G}}, S_{l_{1}}, \ldots, S_{l_{n_{l}}}\right]^{T}
$$

where $n p q$ and $n_{l}$ are the number of PQ buses and transmission lines. $S_{l}$ and $n_{l}$ are the loading of transmission lines and the number of transmission lines, respectively.

$u$ is a vector consisting of control variables, $\left(P_{G_{i}}\right)$ is the real power of all generators excluding swing generator, $\left(V_{G_{i}}\right)$ is the voltage magnitude of generators, (TS) is the branch transformer tap, and $\left(Q_{C}\right)$ is the shunt capacitor. $u$ can be expressed as follows [14,35]:

$$
u=\left[P_{G_{2}}, \ldots, P_{G_{N G}}, V_{G_{1}}, \ldots, V_{G_{N G}}, Q_{C 1}, \ldots, Q_{C N_{c}}, T S_{1}, \ldots, T S_{N_{T}}\right]^{T}
$$

where, $N G, N_{c}$ and $N_{T}$ are the number of generators, shunt VAR compensator and transformers, respectively.

\subsection{Objective Functions of $O P F$}

Here, the first four cases dealt with solving single objective OPF and the last one addressed the multi-objective OPF. 
- $\quad$ Case 1: real power loss minimization

Due to the presence of the inherent resistance for the transmission lines, the aim of this function is to minimize the active power losses and it is expressed as [14,35]:

$$
f_{o}(x, u)=P_{\text {loss }}=\sum_{q=1}^{n l} G_{q_{(i j)}}\left(V_{i}^{2}+V_{j}^{2}-2 V_{i} V_{j} \cos \left(\delta_{i j}\right)\right)
$$

where $G_{q(i j)}$ is the conductance of $q_{t h}$ transmission line, and $V_{i}$ and $V_{j}$ are the voltage magnitude of terminal buses of transmission line.

- Case 2: emission index minimization

In the present case, the target is to reduce the harmful gases emission from the thermal generation units, and the coefficients of the gas emission of the thermal power generators are given in Table 1 . Emission in tons per hour $(\mathrm{t} / \mathrm{h})$ can be described by $[14,35]$ :

$$
\left.f_{o}(x, u)=E=\sum_{i=1}^{N G}\left[\left(\alpha_{i}+\beta_{i} P_{G_{i}}+\gamma_{i} P_{G_{i}}^{2}\right) * 0.01+\omega_{i} e^{\mu i P_{G_{i}}}\right)\right]
$$

where $\alpha, \beta, \gamma, \omega$ and $\mu$ are the emission coefficients and G1,G2,G3,G4,G5, and G6 represent thermal power generators at buses $1,2,5,8,11$, and 13, respectively, as given in Table 1 .

Table 1. Emission coefficients of thermal power generating units [14,35].

\begin{tabular}{lllllll}
\hline Generator & Bus & $\alpha$ & $\beta$ & $\gamma$ & $\omega$ & $\boldsymbol{\mu}$ \\
\hline G1 & 1 & 4.091 & -5.554 & 6.49 & 0.0002 & 2.857 \\
G2 & 2 & 2.543 & -6.047 & 5.638 & 0.0005 & 3.333 \\
G3 & 5 & 4.258 & -5.094 & 4.586 & 0.000001 & 8 \\
G4 & 8 & 5.326 & -3.55 & 3.38 & 0.002 & 2 \\
G5 & 11 & 4.258 & -5.094 & 4.586 & 0.000001 & 8 \\
G6 & 13 & 6.131 & -5.555 & 5.151 & 0.00001 & 6.667 \\
\hline
\end{tabular}

- $\quad$ Case 3: Basic fuel cost minimization

The relationship between fuel cost $(\$ / h)$ and the power generated from the thermal generating units can be approximately given by the quadratic relationship and it is expressed as $[14,35]$ :

$$
f_{o}(x, u)=F C=\sum_{i=1}^{N G} a_{i}+b_{i} P_{G_{i}}+c_{i} P_{G_{i}}^{2}
$$

where $a_{i}, b_{i}, c_{i}$ are the cost coefficient of the thermal generators and these coefficients are provided in Table 2.

Table 2. Cost coefficients of the thermal power generators [14,35].

\begin{tabular}{lllll}
\hline Generator & Bus & $\mathbf{a}$ & $\mathbf{b}$ & $\mathbf{c}$ \\
\hline G1 & 1 & 0 & 2 & 0.00375 \\
G2 & 2 & 0 & 1.75 & 0.0175 \\
G3 & 5 & 0 & 1 & 0.0625 \\
G4 & 8 & 0 & 3.25 & 0.00834 \\
G5 & 11 & 0 & 3 & 0.025 \\
G6 & 13 & 0 & 3 & 0.025 \\
\hline
\end{tabular}

- $\quad$ Case 4: Voltage deviation minimization

The voltage deviation index is the cumulative deviation of all load buses from nominal value of 
unity. It also plays a significant role in keeping the voltage quality and security of the electrical power network. This case is expressed as [14,35]:

$$
f_{o}(x, u)=V D=\left(\sum_{p=1}^{N L}\left|V_{L_{p}}-1\right|\right)
$$

- Case 5: Minimization of basic the fuel cost, emission index, voltage deviation and the real power losses.

The aim of this case is to reduce quadratic fuel cost, active power transmission losses, environmental emission index and voltage deviation index simultaneously. It can be defined as follows $[14,35]$ :

$$
f_{o}(x, u)=F C+\lambda_{p} \times P_{\text {loss }}+\lambda_{V D} \times V D+\lambda_{E} \times E
$$

where $\lambda_{p}, \lambda_{V D}$ and $\lambda_{E}$ are weight factors and they are assumed to be 22, 21 and 19, respectively as in [14].

\subsection{Constraints}

The constraints of OPF are usually categorized into [14,35]:

1. Equality constraints

The equality constraints of OPF are usually represented by the load flow equations:

$$
\begin{gathered}
P_{G_{i}}-P_{D_{i}}=V_{i} \sum_{k=1}^{N_{B}} V_{k}\left(G_{i k} \cos \theta_{i k}+B_{i k} \sin \theta_{i k}\right) \\
Q_{G_{i}}-Q_{D_{i}}=V_{i} \sum_{k=1}^{N_{B}} V_{k}\left(G_{i k} \sin \theta_{i k}-B_{i k} \cos \theta_{i k}\right)
\end{gathered}
$$

where $P_{D_{i}}, Q_{D_{i}}, N_{B}$, and $\theta_{i k}$ are the active and reactive load demand, the number of buses and the angle difference between bus i and k, respectively. $G_{i k}$ and $B_{i k}$ are the transfer and susceptance conductance.

2. Inequality constraints

It can be defined by operating limits on the equipment of the power system, transmission loading and voltage of load buses.

(a) Constraints of thermal and renewable energy generating units

$$
\begin{aligned}
V_{G_{i, \text { min }}} & \leq V_{G_{i}} \leq V_{G_{i, \max }} i=1, \ldots, N \\
P_{G_{i, \text { min }}} & \leq P_{G_{i}} \leq P_{G_{i, \text { max }}} i=1, \ldots, N \\
Q_{G_{i, \text { min }}} & \leq Q_{G_{i}} \leq Q_{G_{i, \text { max }}} i=1, \ldots, N
\end{aligned}
$$

(b) Constraints of the transformer tap setting

$$
T S_{k, \min } \leq T S_{k} \leq T S_{k, \max } k=1, \ldots, N_{T}
$$

(c) constraints of the shunt compensator

$$
Q_{C, j, \min } \leq Q_{C} \leq Q_{C, j, \max } j=1, \ldots, N_{C}
$$

(d) Constraints of the voltages at load buses

$$
V_{L r, \min } \leq V_{L r} \leq V_{L r, \max } r=1, \ldots, N_{L}
$$


(e) Constraints of the transmission line loading

$$
S_{l v} \leq S_{l v, \max } v=1, \ldots, n_{l}
$$

\subsection{Constraint Handling}

In order to decline the infeasible solutions of OPF and keep the dependent variables within the allowable ranges, a penalty function was modeled and added to the objective functions defined in Section $2.2[14,35]$.

$$
\text { penalty }=K_{p}\left(P_{G 1}-P_{G 1}^{L i m}\right)^{2}+K_{Q} \sum_{i=1}^{N G}\left(Q_{G i}-Q_{G i}^{L i m}\right)^{2}+K_{V} \sum_{i=1}^{N L}\left(V_{L i}-V_{L i}^{L i m}\right)^{2}+K_{S} \sum_{i=1}^{n l}\left(S_{l i}-S_{L i}^{L i m}\right)^{2}
$$

where $K_{Q}, K_{p}, K_{V}$ and $K_{S}$ are the values of penalty factors associated with generation reactive power, generation real power of the swing generator, load bus voltages and line flow of transmission lines. They are assumed to be 100,100,100, and 100,000, respectively [14,36], and $x^{\text {Lim }}$ is the value of the violated limit of dependent variables $(x)$. It is equal to $x^{\max }$ in case of $x>x^{\max }$ or $x^{\min }$ in case of $x<x^{\min }$.

\section{Mathematical Models of the Wind and Solar Power Generating Units}

\subsection{Wind Power Units}

\subsubsection{Uncertain and Power Model of Wind Turbines}

The wind speed of the wind turbines follows the Weibull probability distribution function. The characteristic of the output power generated by the wind turbine is a random variable depending on wind speed. The Weibull probability distribution function with dimensionless shape factor $(k)$ and scale factor $(c)$ is used to model the wind speed $f_{v}(v)$. The wind speed $\left(f_{v}(v)\right)$ can be expressed mathematically as $[1,2,37,38]$ :

$$
f_{v}(v)=\frac{k}{c}\left(\frac{v}{c}\right)^{k-1} \times e^{-\left(\frac{v}{c}\right)^{k}}
$$

The electrical energy generated by a wind turbine is the result of converting the kinetic energy of wind. The actual output power of wind turbines $\left(P_{w}(v)\right)$ can be presented as $[1,2,37,38]$ :

$$
P_{w}(v)= \begin{cases}0 & v<v_{\text {in }} \text { and } v>v_{\text {out }} \\ P_{w r}\left(\frac{v-v_{\text {in }}}{v_{r}-v_{\text {in }}}\right) & v_{\text {in }} \leq v \leq v_{r} \\ P_{w r} & v_{r}<v \leq v_{\text {out }}\end{cases}
$$

where $\left(P_{w r}\right),\left(v_{\text {in }}\right),\left(v_{\text {out }}\right)$ and $\left(v_{r}\right)$ are the rated power of the wind turbine, the cut-in wind speed of the wind turbine, the cut-out wind speed and the rated wind speed, respectively.

\subsubsection{Calculation of Direct, Underestimation and Overestimation Cost of Wind Power}

The direct cost of wind power plant can be defined as [4,39-41]:

$$
C_{w, j}\left(P_{w s, j}\right)=g_{j} P_{w s, j}
$$

where $g_{j}$ is the direct cost coefficient of wind plant.

The cost function is overestimated because the actual generated power from the wind turbine is less than the estimated power by mathematical equations. The overestimation cost is used for reverse 
the requirements when the estimated output power of the wind turbine is more than actual output power. Reserve cost for the $j^{\text {th }}$ wind turbine can be defined as [4,39-41]:

$$
\begin{array}{r}
C_{R w, j}\left(P_{w s, j}-P_{w a v, j}\right)=K_{R w, j}\left(P_{w s, j}-P_{w a v, j}\right) \\
=K_{R w, j} \int_{0}^{P_{w w, j}}\left(P_{w s, j}-P_{w, j}\right) f_{w}\left(P_{w, j}\right) d P_{w, j}
\end{array}
$$

where $K_{R w, j}, P_{w a v, j}, P_{w s, j}$ and $f_{w\left(P_{w, j}\right)}$ are the reserve cost coefficient pertaining to the $j^{\text {th }}$ wind turbine, the actual available power from the same plant, the estimated power from the $j^{\text {th }}$ wind turbine and the wind power probability density function for $j^{\text {th }}$ wind turbine.

Underestimation cost function of the wind turbine is due to not using the whole power which is generated from the wind turbine. In other words, when the generated power from the wind turbine is more than the estimated power, the underestimation cost function is applied as a penalty due to wasting the surplus power. The penalty cost for the $j^{\text {th }}$ wind turbine can be defined as [4,39-41]:

$$
\begin{gathered}
C_{P w, j}\left(P_{w a v, j}-P_{w s, j}\right)=K_{P w, j}\left(P_{w a v, j}-P_{w s, j}\right) \\
=K_{P w, d} \int_{P_{w s, j}}^{P_{w r, j}}\left(P_{w, j}-P_{w s, j}\right) f_{w}\left(P_{w, j}\right) d P_{w, j}
\end{gathered}
$$

where $K_{P w, j}$ is a coefficient representing the penalty cost of the $j^{\text {th }}$ wind turbine and $P_{w r, j}$ is the rated output power which is generated from the $j^{\text {th }}$ wind turbine. As shown in Section 3.1.2, the total cost of wind power turbines $\left(C_{T}^{W}\right)$ can be described as follows:

$$
C_{T}^{W}=\sum_{j=1}^{N_{w w}} C_{w, j}\left(P_{w s, j}\right)+C_{R w, j}\left(P_{w s, j}-P_{w a v, j}\right)+C_{P w, j}\left(P_{w a v, j}-P_{w s, j}\right)
$$

where $N_{w}$ is the number of wind power turbines.

\subsection{Solar Power Units}

\subsubsection{Uncertain and Power Model of Solar PV Plants}

Solar irradiance can be modelled by lognormal probability distribution function due to its uncertain and stochastic nature. The lognormal probability distribution is a function of solar irradiance (G) with mean $\mu$ and standard deviation $\sigma$, it can be expressed mathematically as [3,4]:

$$
f_{G}(G)=\frac{1}{G \sigma \sqrt{2 \pi}} \exp \left(\frac{-(\ln x-\mu)^{2}}{2 \sigma^{2}}\right) G>0
$$

The main role of PV systems is to convert the solar irradiance to electrical energy. The output power of PV system $\left(P_{S}(G)\right)$ as a function of irradiance can be estimated as [4,39]:

$$
P_{s}(G)= \begin{cases}P_{s r} \frac{G^{2}}{G_{s t d} R_{c}} & \text { for } 0<G<R_{c} \\ P_{s r} \frac{G}{G_{s t d}} & \text { for } G \geq R_{c}\end{cases}
$$

where $G_{s t d}$ represents the solar irradiance in standard environment, $R_{c}$ is a certain irradiance point, and $P_{s r}$ is the rated output power which is generated from the solar PV system. 
3.2.2. Calculation of Direct, Underestimation, and Overestimation Cost of Solar PV Power

The direct cost of solar power plant can be defined as [4,39]:

$$
C_{s, k}\left(P_{s s, k}\right)=h_{k} P_{s s, k}
$$

where $h_{k}$ is a coefficient which represents the direct cost of the solar photovoltaic plant.

The same case as in the wind energy system, the solar energy system involves overestimation and underestimation cost due to its uncertain output power. Reserve cost for the overestimation of $k^{\text {th }}$ solar PV system is [4,39]:

$$
\begin{array}{r}
C_{R s, k}\left(P_{s s, k}-P_{s a v, k}\right)=K_{R s, k}\left(P_{s s, k}-P_{s a v, k}\right) \\
=K_{R s, k} * f_{s}\left(P_{s a v, k}<P_{s s, k}\right) * \\
{\left[P_{s s, k}-E\left(P_{s a v, k}<P_{s s, k}\right)\right]}
\end{array}
$$

where $K_{R s, k}$ is a coefficient which represents the reserve cost pertaining to $k^{\text {th }}$ solar PV system, $P_{s a v, k}$ is the actual available power from the same plant, $f_{s}\left(P_{s a v}, k<P_{s s, k}\right)$ is the probability of solar power shortage occurrence than the scheduled power $\left(P_{s s, k}\right)$ and $E\left(P_{s a v, k}<P_{s s, k}\right)$ is the expectation of solar PV power below $P_{s s, k}$.

In the case of the underestimation of $k^{\text {th }}$ solar PV system, the penalty cost is given as $[4,39]$ :

$$
\begin{array}{r}
C_{P s, k}\left(P_{s a v, k}-P_{s s, k}\right)=K_{P_{s, k}}\left(P_{s a v, k}-P_{s s, k}\right) \\
=K_{P s, k} * f_{s}\left(P_{s a v, k}>P_{s s, k}\right) * \\
{\left[E\left(P_{s a v, k}>P_{s s, k}\right)-P_{s s, k}\right]}
\end{array}
$$

where $K_{P s, k}$ is a coefficient represents the penalty cost pertaining to $k^{\text {th }}$ solar PV system, $f_{s}\left(P_{s a v, k}<P_{s s, k}\right)$ is the probability of solar power surplus than the scheduled power $\left(P_{s s, k}\right)$ and $E\left(P_{s a v, k}<P_{s s, k}\right)$ is the expectation of solar PV power above $P_{s s, k}$. As explained in Section 3.2.2, the total cost of solar PV plants $\left(C_{T}^{P V}\right)$ consists of three terms (direct, underestimation and overestimation cost) and it can be given as follows $[4,39]$ :

$$
C_{T}^{P V}=\sum_{k=1}^{N_{P V}} C_{s, k}\left(P_{s s, k}\right)+C_{P s, k}\left(P_{s a v, k}-P_{s s, k}\right)+C_{R s, k}\left(P_{s s, k}-P_{s a v, k}\right)
$$

where $N_{P V}$ is the number of the solar PV plants.

\section{Proposed EO}

\subsection{Inspiration and Mathematical Model}

The main inspiration for this algorithm is the dynamic mass balance equation which describes the conservation of mass that enters, leaves or generates in a control volume. This equation is a first-order ordinary differential equation and it is described as the following [34]:

$$
V \frac{d C}{d t}=Q C_{e q}-Q C+G
$$

where $V \frac{d C}{d t}$ is the rate of change of mass in volume, $(V), C$ is the concentration inside the volume $(V)$, $V$ is the control volume, $Q$ is the volumetric flow rate into and out of the control volume, $C_{e q}$ is the concentration at an equilibrium state, and $G$ is the mass generator rate inside the control volume. 
After reaching the steady equilibrium state of Equation (31) that is reformulated as a function of $\left(\frac{Q}{V}\right)$, which is called turnover rate $\left(\lambda=\frac{Q}{V}\right)$. The following equations are derived from Equation (31) to solve for $(C)$ as a function of time $(t)[34]$ :

$$
\begin{gathered}
\frac{d C}{\lambda C_{e q}-\lambda C+\frac{G}{V}}=d t \\
\int_{C_{0}}^{C} \frac{d C}{\lambda C_{e q}-\lambda C+\frac{G}{V}}=\int_{t_{0}}^{t} d t \\
F=e^{-\lambda\left(t-t_{0}\right)} \\
C=C_{e q}+\left(C_{0}-C_{e q}\right) F+\frac{G}{\lambda V}(1-F)
\end{gathered}
$$

where $F$ is an exponential term to assist $\mathrm{EO}$ having a balance between exploitation and exploration, $t_{0}$ is the initial start time, and $C_{0}$ is the initial concentration.

The Equation (35) introduces three rules for updating the concentration of each particle. The equilibrium concentration is the first term which is described as one of the best-so-far solutions randomly chosen from the equilibrium pool. The difference between a concentration of a particle and the equilibrium state is the second term which helps particles to globally explore the domain. The final term is called the generation rate which mainly acts as an exploiter or solution refiner [34].

\subsection{The Interaction between Each Term and the Search Pattern and the Definition of the EO's Terms}

\subsubsection{Initialization and Function Evaluation}

Firstly, the optimization process starts with the initial population. The Equation (36) describes the initial concentration process which depends on the number of particles and dimensions that are initialized in the search space in a uniform random manner [34].

$$
C_{i}^{\text {initial }}=C_{\text {min }}+\operatorname{rand}_{i}\left(C_{\max }-C_{\min }\right)
$$

where $C_{i}^{\text {initial }}$ is the initial concentration vector of the ith particle, $C_{\min }$ is the minimum value for the dimensions, $C_{\max }$ is the maximum value for the dimensions and $r a n d_{i}$ is a random vector ranging between zero and one. After that, the fitness function of the particles are evaluated and then solved to determine the equilibrium conditions.

\subsubsection{Equilibrium Pool and Candidates $\left(C_{E q}\right)$}

The global optimum of EO is represented by the equilibrium state. At the beginning, no information about the equilibrium state exists, but equilibrium candidates are identified to provide a search domain for the particles. There are five equilibrium candidates as given in Equation (37). Four of them are the best-so-far particles determined during the optimization process and the last one is the arithmetic mean of the previous-mentioned four particles. The main goal of the first four candidates is to improve the exploration capability, whereas the fifth candidate enhances the exploitation [34]

$$
\begin{aligned}
C_{a v g} & =\left(\vec{C}_{e q}(1)+\vec{C}_{e q}(2)+\vec{C}_{e q}(3)+\vec{C}_{e q}(4)\right) / 4 \\
C_{e q, p o o l} & =\left\{\vec{C}_{e q}(1), \vec{C}_{e q}(2), \vec{C}_{e q}(3), \vec{C}_{e q}(4), \vec{C}_{(a v e)}\right\}
\end{aligned}
$$




\subsubsection{Exponential Term $(F)$}

The exponential term (F) helps EO to have an acceptable balance between exploration and exploitation. Referring back to Equation (34), the time (t) in Equation (34) depends on the iteration (Iter) and it is described as follows [34]:

$$
t=\left(1-\frac{\text { Iter }}{\text { Maxiter }}\right)^{\left(a_{2} \frac{\text { Iter }}{\text { Maxiter }}\right)}
$$

For the purpose of convergence, $t_{0}$ in Equation (10) is proposed to slow down the search speed as well as enhancing the exploration and exploitation ability of EO [34].

$$
t_{0}=\frac{1}{\vec{\lambda}} \ln \left(-a_{1} \operatorname{sign}(\vec{r}-0.5)\left[1-e^{-\vec{\lambda} t}\right]\right)
$$

where $a_{1}$ and $a_{2}$ are constant values for controlling exploration and exploitation ability, $\operatorname{sign}(\vec{r}-0.5)$ is a factor that determines the direction of exploration and exploitation and $r$ is a random vector ranges between zero and one.

\subsubsection{The Generation Rate $(G)$}

The generation rate aims to provide the exact solution by enhancing the exploitation ability of EO and can be described as [34]:

$$
\vec{G}=\overrightarrow{G_{0}} e^{-\vec{k}\left(t-t_{0}\right)}
$$

After assumption that $k=\lambda$, the equation of generation rate was updated as follows [34]:

$$
\begin{gathered}
\vec{G}=\overrightarrow{G_{0}} \vec{F} \\
\overrightarrow{G_{0}}=\overrightarrow{G C P}\left(\overrightarrow{C_{e q}}-\vec{\lambda} \vec{C}\right) \\
\overrightarrow{G C P}= \begin{cases}0.5 r_{1}, & r_{2} \geq G P \\
0, & r_{2} \geq G P\end{cases}
\end{gathered}
$$

where $r_{1}$ and $r_{2}$ are a random number between zero and one, GCP is the generation rate control parameter.

The generation rate control parameter (GCP) mainly depends on generation probability (GP) which defines the number of particles of the generation term to update their states.

State of the art state that EO at GP $=0.5 ; \mathrm{EO}$ can achieve a good balance between exploration and exploitation. The updating rule of $\mathrm{EO}$ is given as:

$$
\vec{C}=\overrightarrow{C_{e q}}+\left(\vec{C}-\overrightarrow{C_{e q}}\right) \vec{F}+\frac{\vec{G}}{\vec{\lambda} V}(1-\vec{F})
$$

The second and third terms of Equation (45) can increase variation and thus help EO to better explore in case of they have same signs or to decrease the variation and aiding EO in local searches in case of having opposite signs [34].

\subsubsection{Particle's Memory Saving}

This can help each particle track with its coordinates in the space. It aids EO in exploitation capability and avoids getting trapped in local minima [34]. 


\subsection{Implementation of EO to Solve the OPF Problem}

The proposed EO is applied to solve OPF problem including wind and solar PV generation units. The following pseudo code and flowchart shown in Figure 1 explain the steps of the application of EO for OPF problem.

1. Define the control and dependent variables and their limits, as well as the target objective function defined in Section 2.2 [34].

2. Collect and read the input data of the power system under test, such as data of transmission lines, transformers, shunt VAR compensator, loads and generation units.

3. Calculate the estimated output power of solar PV and wind power generation units, as defined and explained in Section 3 [34].

4. Initialize the particle's populations [34].

5. Assign a large number to the fitness of equilibrium candidates and let a1 = 2; a2 = 1; GP = $0.5[34]$.

6. Do the main while loop as the following [34]:

(a) While (current iteration (Iter) <maximum number of iteration (Max-iter))

(b) For i=1: particles' number (n)

(c) Find the fitness value of the $i_{\text {th }}$ particle

i. If fitness $\left(C_{i}\right)<$ fitness $\left(C_{e q 1}\right)$ then

Substitute $\left(C_{e q 1}\right)$ with $\left(C_{i}\right)$ and fitness $\left(C_{e q 1}\right)$

with fitness $\left(C_{i}\right)$

ii. $\quad$ Else if fitness $\left(C_{i}\right)>$ fitness $\left(C_{e q 1}\right)$ \& fitness $\left(C_{i}\right)<$ fitness $\left(C_{e q 2}\right)$ then

Substitute $\left(C_{e q 2}\right)$ with $\left(C_{i}\right)$ and fitness $\left(C_{e q 2}\right)$

with fitness $\left(C_{i}\right)$

iii. $\quad$ Else if fitness $\left(C_{i}\right)>$ fitness $\left(C_{e q 1}\right) \&$ fitness $\left(C_{i}\right)$

$>$ fitness $\left(C_{e q 2}\right) \&$ fitness $\left(C_{i}\right)<$ fitness $\left(C_{e q 3}\right)$ then

Substitute $\left(C_{e q 3}\right)$ with $\left(C_{i}\right)$ and fitness $\left(C_{e q 3}\right)$

with fitness $\left(C_{i}\right)$

iv. $\quad$ Else if fitness $\left(C_{i}\right)>$ fitness $\left(C_{e q 1}\right)$ \& fitness $\left(C_{i}\right)>$ fitness $\left(C_{e q 2}\right) \&$ fitness $\left(C_{i}\right)>$ fitness $\left(C_{e q 3}\right)$ \& fitness $\left(C_{i}\right)<$ fitness $\left(C_{e q 4}\right)$ then

(d) End (if )

Substitute $\left(C_{e q 4}\right)$ with $\left(C_{i}\right)$ and fitness $\left(C_{e q 4}\right)$ with fitness $\left(C_{i}\right)$

(e) $\operatorname{End}($ for)

7. Find the $\overrightarrow{C_{a v g}}$ according to Equation (37).

8. Construct the equilibrium pool according to Equation (38) [34].

9. In case of the current iteration $>1$, accomplish memory saving [34].

10. Assign $t$ according to Equation (39).

11. Do the second for loop as following:

For $\mathrm{i}=1$ : particles' number

(a) Select one candidate from the equilibrium pool randomly.

(b) Create the two random vector $(\lambda$ and $r)$.

(c) Construct F, GCP, $G_{0}$ and $G$ according to the Equations (34) and (42)-(44), respectively [34].

(d) Update the concentration $C$ according to Equation (45)

End the second for loop.

12. Increase the current iteration by one.

13. End the main while loop.

14. Extract and analyse of the results. 


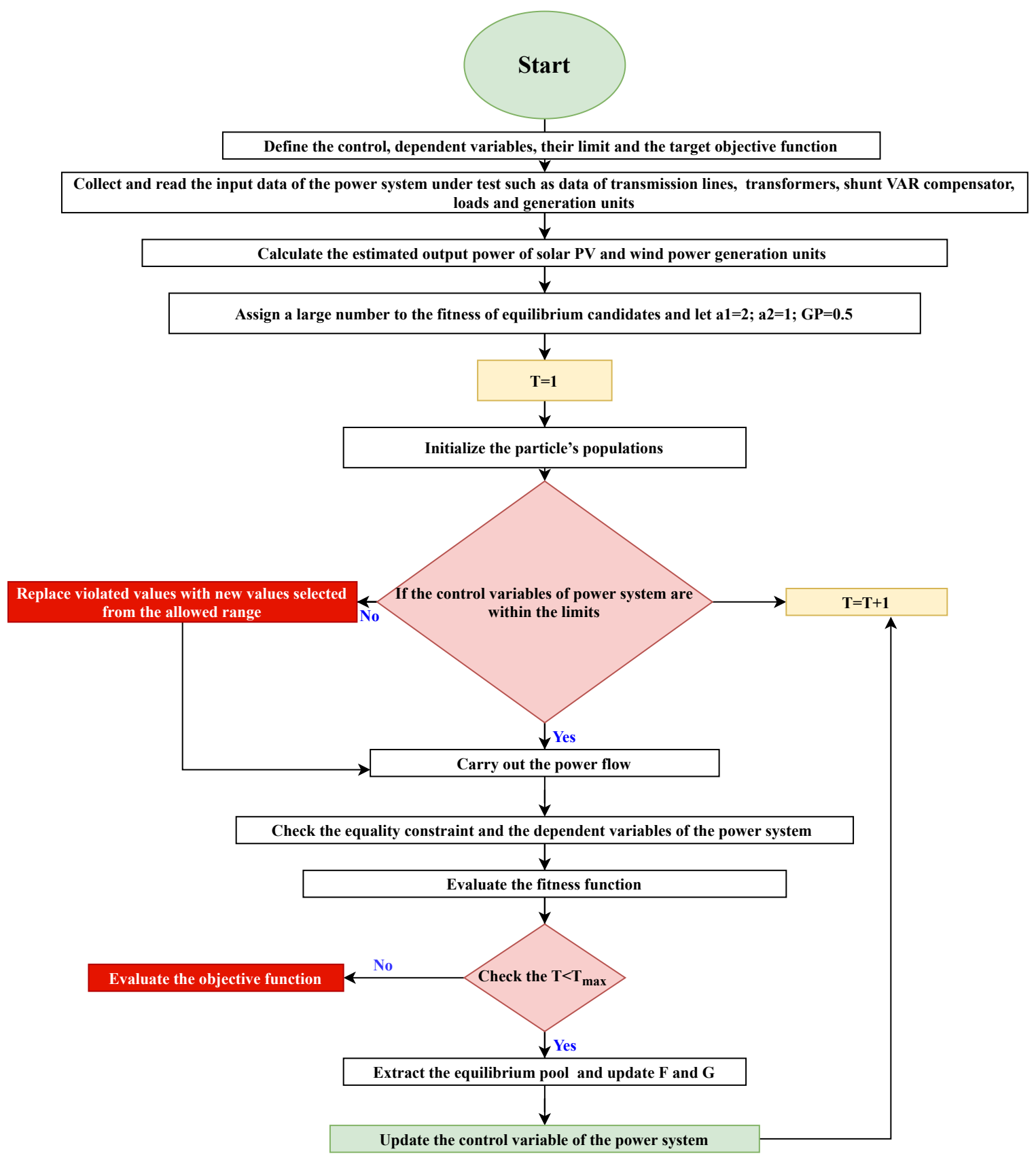

Figure 1. Flowchart of implementation of EO to solve OPF problem.

\section{Test Systems and Control Parameters of Optimization Methods}

\subsection{Description of the Test Power Systems}

- Test system 1: IEEE 30-bus system

The IEEE 30-bus system consists of six thermal power generators, as presented in Figure 2. The data about transmission lines, tap changing transformers, AVR compensators, limitations on generators and load voltages, active and reactive power demand are given in [42-44]. The general specifications of this system are described in Table 3. 
Table 3. The general specification of all test power systems.

\begin{tabular}{lcccc}
\hline \multicolumn{5}{c}{ Values and Details } \\
\hline Characteristics & Test System 1 [42-44] & Test System 2 & Test System 3 & Test System 4 \\
\hline Buses & 30 & 30 & 30 & 30 \\
\hline Transmission Lines & 41 & 41 & 41 & 41 \\
\hline Limitation on generator voltage & {$[0.9-1.1]$} & {$[0.9-1.1]$} & {$[0.9-1.1]$} & {$[0.9-1.1]$} \\
\hline Limitation on load voltage & {$[0.95-1.1]$} & {$[0.95-1.1]$} & {$[0.95-1.1]$} & {$[0.95-1.1]$} \\
\hline Thermal power generators & 6 & 3 & 3 & 3 \\
\hline Wind power plants & 0 & 2 & 0 & 5 \\
\hline Solar power plants & 0 & 3 & 5 & 0 \\
\hline Shunt VAR compensation & 9 & 9 & 9 & 9 \\
\hline Transformer with tap ratio & 4 & 4 & 4 & 4 \\
\hline Control Variables & 24 & 28 & 28 & 28 \\
\hline Active and Reactive power demand & $283.4 \mathrm{MW}, 126.2 \mathrm{Mvar}$ & $283.4 \mathrm{MW}, 126.2 \mathrm{Mvar}$ & $283.4 \mathrm{MW}, 126.2 \mathrm{Mvar}$ & $283.4 \mathrm{MW}, 126.2 \mathrm{Mvar}$ \\
\hline
\end{tabular}

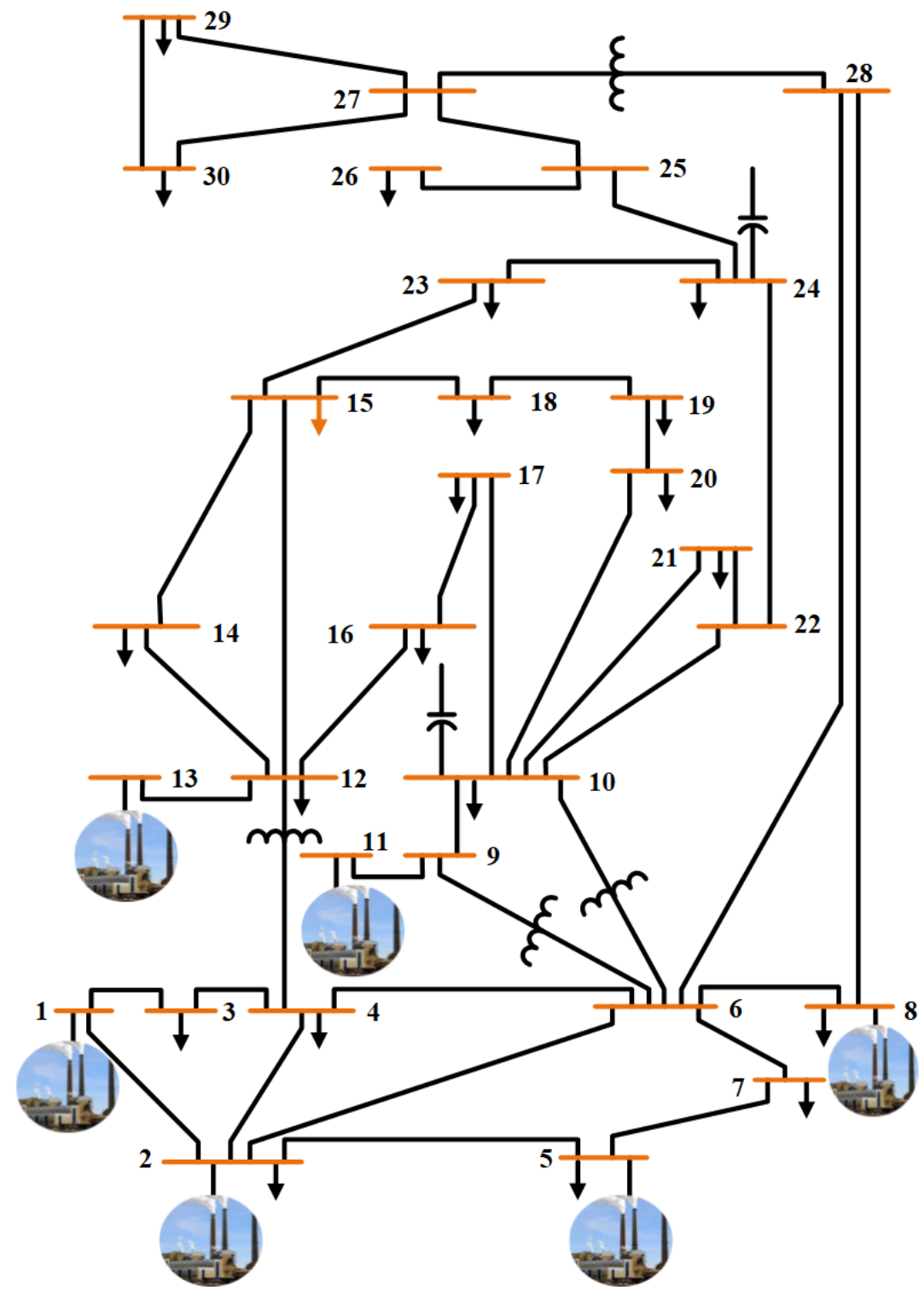

Figure 2. scenario 1: IEEE 30-bus system.

- $\quad$ Test system 2: Hybrid wind and solar PV integrated IEEE 30-bus system

This modified test power system is simulated to show its behavior in the presence of both wind 
and solar PV power generating units, as depicted in Figure 3. The IEEE 30-bus system has been modified by replacing the thermal power generating units at buses 5, 11, and 13 with wind generator at bus 11 and solar PV at buses 5 and 13. In addition, the new solar PV and wind power generators are constructed at bus 24 , and 30 , respectively. The objective functions defined in Section 2.2 are modified by adding the output power of solar PV plants $\left(P_{S}(G)\right)$ and the output power of wind plants $\left(P_{w}(v)\right)$ given in Section 3. Case 3 and case 5 described in Section 2.2 are modified by adding the total cost of solar PV plants $\left(C_{T}^{P V}\right)$ and the total cost of wind plants $\left(C_{T}^{w}\right)$ defined in Section 3. The specification of this hybrid power system is given in Table 3. The data of wind and solar PV plants are described in Tables 4 and 5, respectively.

Table 4. Data of wind power plant for Test system 2.

\begin{tabular}{|c|c|c|c|c|c|c|c|c|c|c|c|}
\hline Unit & Bus & No. of Turbines & $P_{w r}[\mathrm{MW}]$ & k & $\mathrm{c}$ & $g_{i}[\$ / M W H]$ & $K_{R w, i}[\$ / M W H]$ & $K_{P w, i}[\$ / M W H]$ & $v_{\text {in }}[\mathrm{m} / \mathrm{s}]$ & $v_{\text {out }}[\mathrm{m} / \mathrm{s}]$ & $v_{r}[\mathrm{~m} / \mathrm{s}]$ \\
\hline 1 & 11 & 12 & 2 & 2 & 9 & 1.7 & 2.8 & 1.7 & 4 & 25 & 13 \\
\hline 2 & 30 & 12 & 2 & 2 & 10 & 1.7 & 2.8 & 1.7 & 4 & 25 & 13 \\
\hline
\end{tabular}

Table 5. Data of solar power plant for Test system 2.

\begin{tabular}{cccccccccc}
\hline Unit & Bus & $P_{s r}[\mathrm{MW}]$ & $G_{s t d}\left[\mathrm{~W} / \mathrm{m}^{2}\right]$ & $R_{c}\left[\mathrm{~W} / \mathrm{m}^{2}\right]$ & $\mu$ & $\sigma$ & $h_{k}[\mathbf{S} / \mathbf{M W h}]$ & $K_{P s, k}[\$ / \mathrm{MWh}]$ & $K_{R s, k}[\$ / \mathrm{MWh}]$ \\
\hline 1 & 5 & 24 & 800 & 170 & 6 & 0.6 & 1.55 & 3.2 & 1.30 \\
\hline 2 & 13 & 30 & 800 & 170 & 6 & 0.6 & 1.45 & 3.1 & 1.45 \\
\hline 3 & 30 & 30 & 800 & 200 & 6 & 0.6 & 1.60 & 3.0 & 1.30 \\
\hline
\end{tabular}

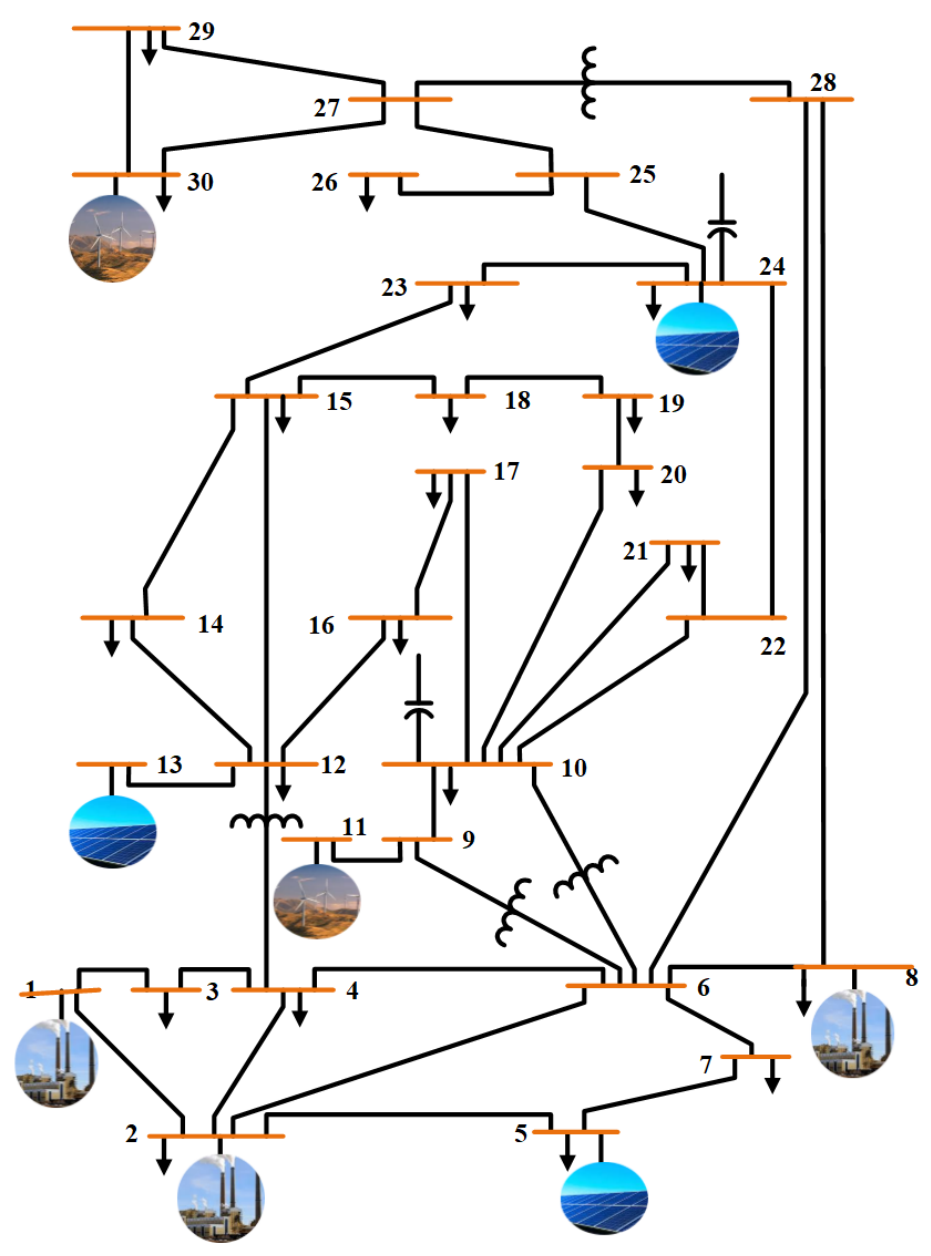

Figure 3. Hybrid wind and solar PV integrated IEEE 30-bus system. 
- $\quad$ Test system 3: Solar PV integrated IEEE 30-bus system

This system is modified by locating solar PV generators at buses 5, 11, and 13 instead of the thermal power generators. Furthermore, two new solar power generation units are installed at buses 24, and 30, as shown in Figure 4. The objective funtions defined in Section 2.2 are modified by adding the output power of solar PV plants $\left(P_{S}(G)\right)$ given in Section 3. Case 3 and case 5 described in Section 2.2 are modified by adding the total cost of solar PV plants $\left(C_{T}^{P V}\right)$ defined in Section 3. The general data of this system and solar PV plants are presented in Tables 3 and 6 , respectively.

Table 6. Data of solar power plant for Test system 3.

\begin{tabular}{cccccccccc}
\hline Unit & Bus & $\boldsymbol{P}_{\boldsymbol{s r}}[\mathrm{MW}]$ & $\boldsymbol{G}_{\text {std }}\left[\mathbf{W} / \mathbf{m}^{2}\right]$ & $\boldsymbol{R}_{\boldsymbol{c}}\left[\mathbf{W} / \mathbf{m}^{2}\right]$ & $\mu$ & $\sigma$ & $\boldsymbol{h}_{\boldsymbol{k}}[\mathbf{\$} / \mathbf{M W h}]$ & $\boldsymbol{K}_{P s, k}[\mathbf{\$} / \mathbf{M W h}]$ & $\boldsymbol{K}_{R s, k}[\mathbf{S} / \mathbf{M W h}]$ \\
\hline 1 & 5 & 24 & 800 & 170 & 6 & 0.6 & 1.55 & 3.2 & 1.30 \\
\hline 2 & 11 & 24 & 800 & 200 & 6 & 0.6 & 1.45 & 2.8 & 1.30 \\
\hline 3 & 13 & 24 & 800 & 170 & 6 & 0.6 & 1.60 & 3.1 & 1.45 \\
\hline 4 & 24 & 30 & 800 & 170 & 6 & 0.6 & 1.60 & 3.0 & 1.30 \\
\hline 5 & 30 & 30 & 800 & 200 & 6 & 0.6 & 1.60 & 3.0 & 1.30 \\
\hline
\end{tabular}

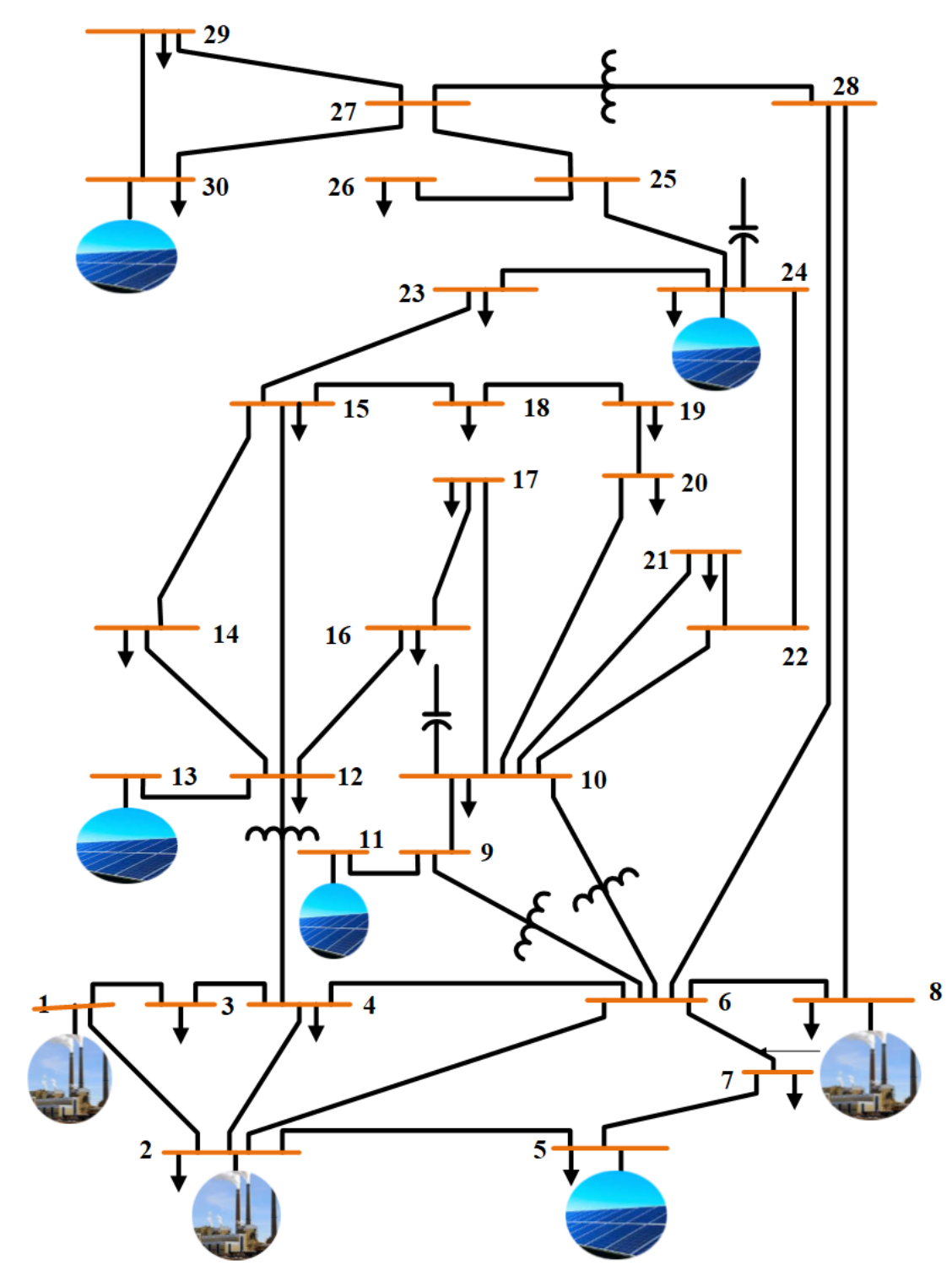

Figure 4. Solar PV integrated IEEE 30-bus system. 
- $\quad$ Test system 4: wind integrated IEEE 30-bus system

In this system, the IEEE 30-bus system is modified by replacing the thermal power generating units at buses 5, 11, and 13 with wind power generators. Moreover, two new wind generators have been added at buses 24, and 30, as seen in Figure 5. The objective functions defined in Section 2.2 is modified by adding the output power of wind plants $\left(P_{w}(v)\right)$ given in Section 3 . Case 3 and case 5 described in Section 2.2 are modified by adding the total cost of wind plants $\left(C_{T}^{w}\right)$ defined in Section 3. The general specifications of this system and the data of wind power plants are given in Tables 3 and 7, respectively.

Table 7. Data of wind power plant for Test system 4 .

\begin{tabular}{cccccccccccc}
\hline Unit & Bus & No. of Turbines & $P_{w r}[\mathbf{M W}]$ & $\mathbf{k}$ & $\mathbf{c}$ & $g_{i}[\mathbf{\$} / \mathbf{M W H}]$ & $K_{R w, i}[\mathbf{\$} / \mathbf{M W H}]$ & $K_{P w, i}[\mathbf{\$} / \mathbf{M W H}]$ & $v_{\text {in }}[\mathbf{m} / \mathbf{s}]$ & $v_{\text {out }}[\mathbf{m} / \mathbf{s}]$ & $v_{r}[\mathbf{m} / \mathbf{s}]$ \\
\hline 1 & 5 & 12 & 2 & 2 & 9 & 1.65 & 2.6 & 1.5 & 4 & 25 & 13 \\
\hline 2 & 11 & 12 & 2 & 2 & 10 & 1.60 & 2.6 & 1.5 & 4 & 25 & 13 \\
\hline 3 & 13 & 12 & 2 & 2 & 9 & 1.60 & 2.6 & 1.5 & 4 & 25 & 13 \\
\hline 4 & 24 & 15 & 2 & 2 & 10 & 1.65 & 2.6 & 1.5 & 4 & 25 & 13 \\
\hline 5 & 30 & 15 & 2 & 2 & 9 & 1.70 & 2.6 & 1.5 & 4 & 25 & 13 \\
\hline
\end{tabular}

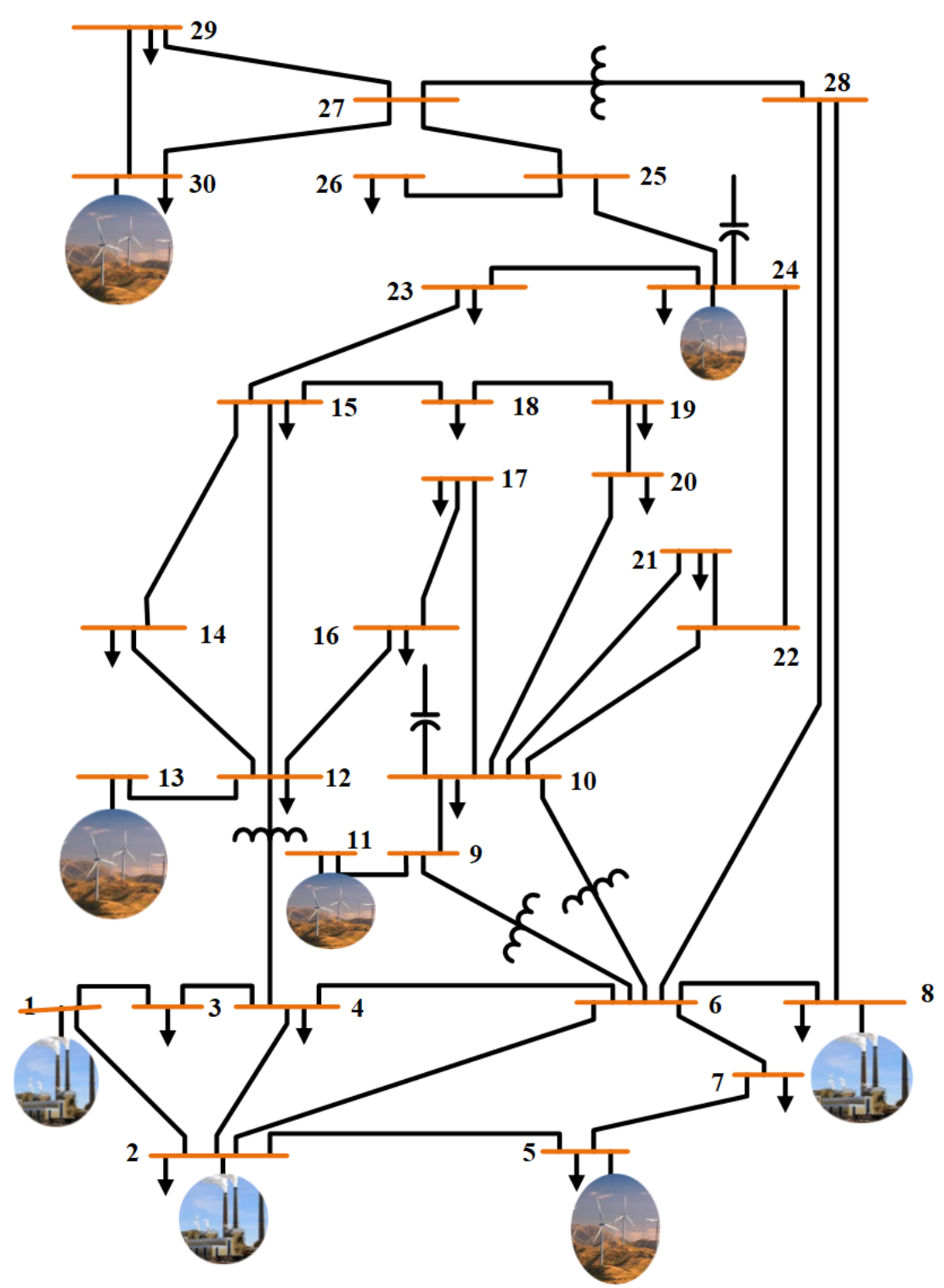

Figure 5. Wind integrated IEEE 30-bus system. 


\subsection{Control Parameters of Optimization Methods}

The number of iterations, population size, testing ranges and other parameters of the optimization methods are given in Table 8.

Table 8. Control parameters values for optimization methods.

\begin{tabular}{|c|c|c|}
\hline Algorithm & Parameters & Values \\
\hline \multirow{5}{*}{ MPSO [45] } & Inertia coefficient $(\mathrm{w})$ & decreasing linearly from 0.9 to 0.4 \\
\hline & Number of search agents & 50 \\
\hline & Maximum number of iteration & 100 \\
\hline & Udapting factor $(\mathrm{C} 1, \mathrm{C} 2)$ & Described in [45] \\
\hline & Acceleration coefficient $(\mathrm{c} 1, \mathrm{c} 2)$ & $\mathrm{c} 1=1, \mathrm{c} 2=2$ \\
\hline \multirow{3}{*}{ TLBO [46] } & Teaching factor & Selected randomly $[1,2]$ \\
\hline & Population size & 50 \\
\hline & Maximum number of iteration & 100 \\
\hline \multirow{5}{*}{ TACPSO [45] } & Inertia coefficient $(\mathrm{w})$ & decreasing linearly from 0.9 to 0.4 \\
\hline & Number of search agents & 50 \\
\hline & Maximum number of iteration & 100 \\
\hline & Udapting factor $(\mathrm{C} 1, \mathrm{C} 2)$ & Described in [45] \\
\hline & Acceleration coefficient $(\mathrm{c} 1, \mathrm{c} 2)$ & $\mathrm{c} 1=1, \mathrm{c} 2=2$ \\
\hline \multirow{3}{*}{ MFO [47] } & Population size & 50 \\
\hline & Maximum number of iteration & 100 \\
\hline & Shape constant (b) & 1 \\
\hline \multirow{5}{*}{ AGPSO 1 [45] } & Inertia coefficient $(w)$ & decreasing linearly from 0.9 to 0.4 \\
\hline & Number of search agents & 50 \\
\hline & Maximum number of iteration & 100 \\
\hline & Udapting factor $(\mathrm{C} 1, \mathrm{C} 2)$ & Described in [45] \\
\hline & Acceleration coefficient $(\mathrm{c} 1, \mathrm{c} 2)$ & $\mathrm{c} 1=1, \mathrm{c} 2=2$ \\
\hline \multirow{5}{*}{ EO [34] } & Constant values for controlling exploration $\left(a_{1}\right)$ & 2 \\
\hline & Constant values for controlling exploitation $\left(a_{2}\right)$ & 1 \\
\hline & Number of search particles & 50 \\
\hline & Maximum number of iteration & 100 \\
\hline & Generation probability & 0.5 \\
\hline
\end{tabular}

\section{Results and Discussion}

The performance and effectiveness of the EO are verified for solving OPF problem by carrying out 20 independent test trial runs for all cases discussed in Section 2.2. The EO [34] and other five metaheuristic optimization techniques: MFO [47], TACPSO [45], AGPSO1 [45], TLBO [46] and MPSO [45] have been tested on four power test systems given in Section 5.1. All these optimization techniques are implemented on 2.8-GHz i7 PC with 16 GB of RAM using MATLAB 2017.

\subsection{Discussion and Analysis of the Objective Functions of OPF}

\subsubsection{Minimization of Real Power Loss}

The EO [34], TLBO [46], MPSO [45], MFO [47], AGPSO1 [45], and TACPSO [45] algorithms are implemented on the test system 1, test system 2, test system 3, and test system 4 for the minimization of the real power loss as defined in Section 2.2. Figure 6a shows the convergence characteristics of real power loss yielded by the best solution of the $\mathrm{EO}$ and other optimization methods for test system 1. It observed that the better convergence characteristic is yielded by the EO. Furthermore, Figure $6 \mathrm{~b}, \mathrm{c}$ display voltage and loading profiles of test system 1 for case 1 . It is clear that the EO and other optimization methods obey the voltage limits of buses and loading limits of transmission lines. The results of EO and other techniques for test system 1 are displayed in Table 9. It can be observed that EO achieves the minimum real power loss, but other optimization techniques such as TLBO and 
MFO have less fuel cost at 967.24 \$/h and 967.44 \$/h, respectively. Furthermore, other techniques have less voltage deviations at minimization this objective function. However, it is clear that the loading of transmission lines for EO is healthy and less than other methods.

Table 9. Results of EO and other methods of case 1 for Test system 1.

\begin{tabular}{ccccccc}
\hline & MFO & TACPSO & AGPSO1 & TLBO & EO & MPSO \\
\hline$V D($ p.u. $)$ & 0.867649 & 0.898003 & 0.898362 & 0.87350728 & 0.917249 & 0.679794 \\
$F C(\$ / \mathrm{h})$ & 967.4482 & 967.6206 & 967.6485 & 967.2492825 & 967.5865 & 967.7676 \\
$P_{\text {loss }}(\mathrm{MW})$ & 3.124412 & 3.100891 & 3.094156 & 3.108417583 & 3.087342 & 3.144079 \\
$E($ ton $/ \mathrm{h})$ & 0.207299 & 0.207259 & 0.207266 & 0.207286164 & 0.207268 & 0.207273 \\
\hline$f_{0}$ & 3.124412 & 3.100891 & 3.094156 & 3.108417583 & 3.087342 & 3.144079 \\
\hline Improvement $(\%)$ & 1.18 & 0.43 & 0.22 & 0.68 & - & 1.81 \\
\hline
\end{tabular}

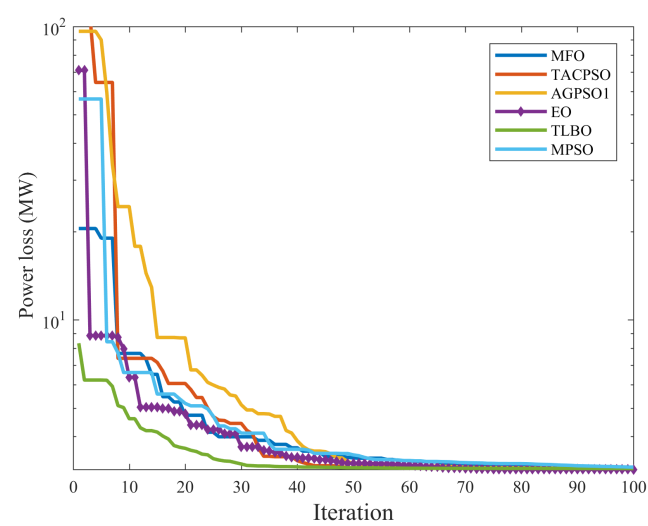

(a) Comparative convergence curves.

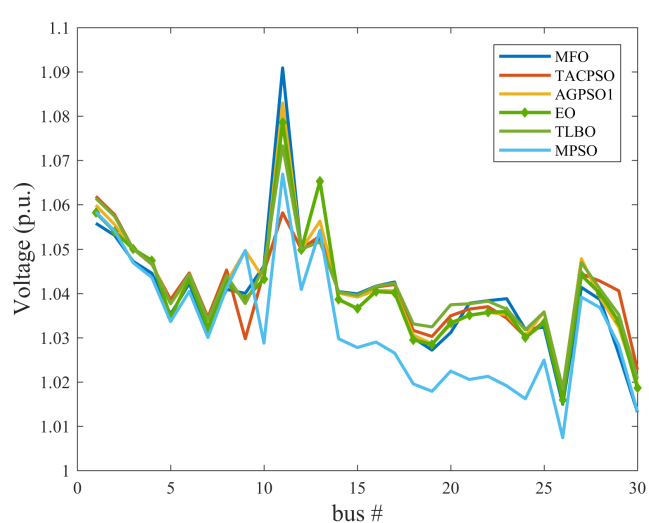

(b) Voltage profile.

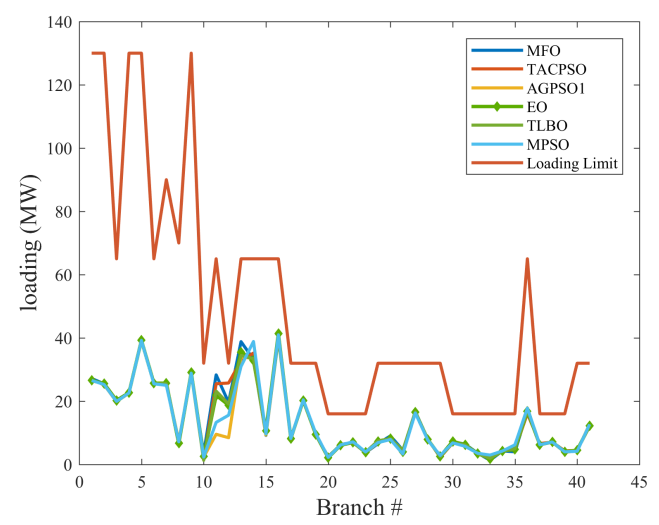

(c) Loading profile.

Figure 6. Comparative convergence, voltage and loading profiles for case 1 for all test systems.

The loss and loading profiles using EO for all test systems are given in Figure 7. The optimal (best) results yielded by the EO method for the test system 1, test system 2, test system 3 , and test system 4 are tabulated in Table 10. From Figure 7 and Table 10, it is seen that the losses of test system 2, test system 3, and test system 4 reduced by $23.6 \%, 31.52 \%$, and $33.32 \%$, respectively, compared to test system 1. Additionally, it can be seen that the contribution of power generation of Test system 2 from wind, solar PV and thermal power generation are 15.05\%, 33.01\%, and 51.93\%, respectively. With respect to Test system 3, the contribution of power generation from solar PV and thermal power are $53.33 \%$ and $46.66 \%$, respectively. Besides, the wind power plants of Test system 4 contributes $52.35 \%$ of the total power generation. 
Table 10. Optimal settings of dependent and control variables for case 1 for all test systems using EO.

\begin{tabular}{|c|c|c|c|c|c|c|}
\hline Parameters & Min & $\operatorname{Max}$ & Test System 1 & Test System 2 & Test System 3 & Test System 4 \\
\hline PG2 (MW) & 20 & 80 & 79.9983006 & 72.14028714 & 48.22886744 & 51.07651611 \\
\hline PG5 (MW) & 15 & 50 & 49.9982627 & 49.99945385 & 49.97347066 & 49.98470056 \\
\hline PG8 (MW) & 10 & 35 & 34.99453958 & 26.20234283 & 34.77838714 & 34.92764479 \\
\hline PG11 (MW) & 10 & 30 & 29.99984469 & 29.42347144 & 29.97517159 & 29.67713532 \\
\hline PG13 (MW) & 10 & 40 & 39.99027741 & 25.72695297 & 29.69711674 & 39.69895071 \\
\hline PG24 (MW) & 10 & 30 & & 18.61010237 & 27.4148297 & 15.73782289 \\
\hline PG30 (MW) & 10 & 40 & & 13.58641689 & 15.23102984 & 14.35575851 \\
\hline V1 (p.u.) & 0.95 & 1.1 & 1.061430345 & 1.033582214 & 1.037749499 & 1.056224426 \\
\hline V2 (p.u.) & 0.95 & 1.1 & 1.057379791 & 1.027683624 & 1.032739079 & 1.051241045 \\
\hline V5 (p.u.) & 0.95 & 1.1 & 1.037622078 & 1.003632229 & 1.013755431 & 1.032812731 \\
\hline V8 (p.u.) & 0.95 & 1.1 & 1.044007621 & 1.015022765 & 1.02707043 & 1.045463882 \\
\hline V11 (p.u.) & 0.95 & 1.1 & 1.073279794 & 1.063216144 & 0.999050197 & 1.042867188 \\
\hline V13 (p.u.) & 0.95 & 1.1 & 1.051619936 & 1.034701938 & 1.044856898 & 1.020563172 \\
\hline V24 (p.u.) & 0.95 & 1.1 & & 1.024480465 & 1.009002895 & 1.020352939 \\
\hline V30 (p.u.) & 0.95 & 1.1 & & 1.022453184 & 1.018925985 & 1.040981535 \\
\hline QC10 (MVAr) & 0 & 5 & 4.287709826 & 4.782286758 & 2.62406261 & 3.612693403 \\
\hline QC12 (MVAr) & 0 & 5 & 2.093601675 & 0.000803534 & 0.986423834 & 2.416935212 \\
\hline QC15 (MVAr) & 0 & 5 & 3.996488379 & 1.898614523 & 0.206692775 & 3.600783886 \\
\hline QC17 (MVAr) & 0 & 5 & 4.136235738 & 4.356883849 & 2.716911629 & 0.342465282 \\
\hline QC20 (MVAr) & 0 & 5 & 4.495134896 & 3.354513668 & 4.692404829 & 3.296807199 \\
\hline QC21 (MVAr) & 0 & 5 & 5.000000000 & 0.046094293 & 2.038284465 & 0.872744865 \\
\hline QC23 (MVAr) & 0 & 5 & 3.197386977 & 4.967912056 & 4.957773966 & 4.740324068 \\
\hline QC24 (MVAr) & 0 & 5 & 4.806462479 & 4.536993047 & 3.79952116 & 3.698494945 \\
\hline QC29 (MVAr) & 0 & 5 & 2.461175597 & 0.21865228 & $4.63994 \mathrm{E}-05$ & 3.927880442 \\
\hline T11 (p.u.) & 0.9 & 1.1 & 1.055740955 & 1.015687471 & 1.020034326 & 1.0962353 \\
\hline T12 (p.u.) & 0.9 & 1.1 & 0.924042761 & 0.951998195 & 0.957069803 & 0.900424717 \\
\hline T15 (p.u.) & 0.9 & 1.1 & 0.988530694 & 0.989254661 & 1.094558386 & 0.991494831 \\
\hline T36 (p.u.) & 0.9 & 1.1 & 0.975749345 & 0.977273155 & 1.010207101 & 1.010623787 \\
\hline PG1 (MW) & 50 & 200 & 51.50611659 & 50.08572807 & 50.22954768 & 50.01396753 \\
\hline QG1 (MVAr) & -20 & 150 & -5.485983591 & -1.712627012 & -9.408754457 & -4.363894439 \\
\hline QG2 (MVAr) & -20 & 60 & 7.574416698 & 7.129014137 & 3.920290677 & 9.504062082 \\
\hline QG5 (MVAr) & -15 & 62.5 & 21.13271229 & 17.01446382 & 19.68757038 & 20.6489489 \\
\hline QG8 (MVAr) & -15 & 48 & 26.41312254 & 26.16274206 & 28.52016815 & 33.06577869 \\
\hline QG11 (MVAr) & -10 & 40 & 19.21231862 & 19.38101083 & 0.13383456 & 18.93870787 \\
\hline QG13 (MVAr) & -15 & 44 & 2.247530335 & 8.029799729 & 33.49981989 & -2.320248965 \\
\hline QG24 (MVAr) & -15 & 44 & & 3.105401958 & 3.720374455 & 2.56415683 \\
\hline QG 30 (MVAr) & -15 & 44 & & 0.296246809 & 2.993820748 & 1.368798025 \\
\hline$V D$ (p.u.) & & & 0.917249187 & 0.367181831 & 0.252949566 & 0.482190403 \\
\hline$F C(\$ / h)$ & & & 967.5864625 & 417.7815499 & 358.1435956 & 368.1354088 \\
\hline$P_{\text {loss }}(\mathrm{MW})$ & & & 3.087341565 & 2.374755583 & 2.128420834 & 2.072496662 \\
\hline$E($ ton $/ \mathrm{h})$ & & & 0.20726839 & 0.09655031 & 0.09111361 & 0.091202895 \\
\hline TC (\$/h) & & & & 863.2203104 & 823.476285 & 867.8385329 \\
\hline$C_{T}^{W}(\$ / h)$ & & & & 141.4837171 & & 499.7031241 \\
\hline$C_{T}^{P V}(\$ / \mathrm{h})$ & & & & 303.9550435 & 465.3326895 & \\
\hline$f_{o}(\mathrm{MW})$ & & & 3.087341565 & 2.374755583 & 2.128420834 & 2.072496662 \\
\hline
\end{tabular}




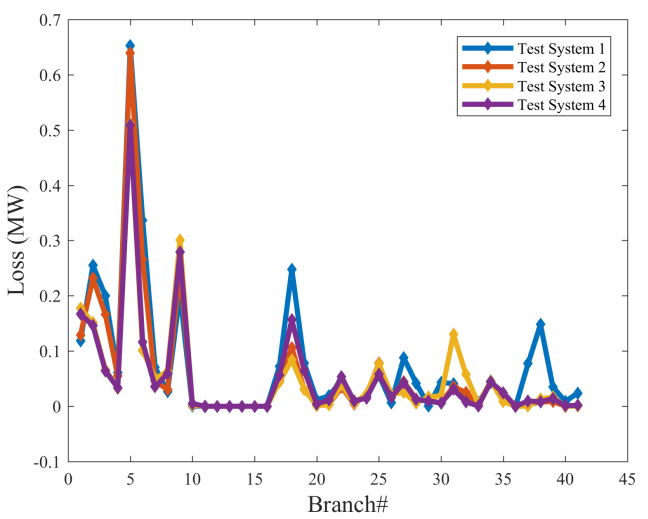

(a) Loss profile.

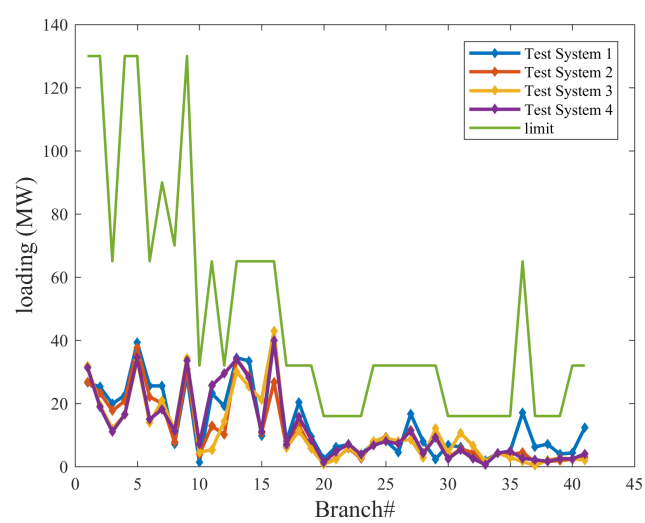

(b) Loading profile.

Figure 7. Loss and loading Profiles of case 1 for all test systems using EO.

The statistical results (the best, the worst, the mean, and the standard deviation) of the real power loss for the EO and other optimization techniques are given in Table 11. As shown in Table 11, the minimum best, standard deviation, and mean are resulted from the EO.

Table 11. Summary of the statistical analysis of case 1 for Test system 1.

\begin{tabular}{ccccc}
\hline & Best & Worst & Mean & Std dev \\
\hline MFO & 3.124412 & 3.469255 & 3.313791 & 0.115148 \\
TACPSO & 3.100891 & 3.495604 & 3.162984 & 0.119564 \\
AGPSO1 & 3.094156 & 3.558659 & 3.136808 & 0.175963 \\
TLBO & 3.108418 & 3.271804 & 3.200392 & 0.057571 \\
EO & 3.087342 & 3.131426 & 3.089549 & 0.013218 \\
MPSO & 3.144079 & 3.417325 & 3.202598 & 0.080901 \\
\hline
\end{tabular}

As expected, the addition and location of the renewable energy resources in the power system have a significant impact on reducing the real power loss.

\subsubsection{Emission Index Minimization}

In this case, the emission index defined in Section 2.2 was minimized for all test systems. Figure 8 demonstrates the convergence characteristics, loss profiles, and loading profiles for emission minimization using EO and other methods. It can be noticed from Figure $8 \mathrm{a}$ that the EO has the smoothest and speediest convergence curves in comparing with other techniques, as well as Figure $8 \mathrm{~b}, \mathrm{c}$ showing that there is no violation in the voltage limits of buses and loading limits of transmission lines. As we can see from Table 13 and Figure 8c that EO can achieve the lowest real power loss and the lowest loading of the transmission lines while minimizing this objective function, but other optimization methods can obtain less voltage deviations in comparison to EO.

The best (optimal) results obtained using the EO for all test systems for case 2 are shown in Table 12. As we can see from Figure 9 and Table 12 that emission index reduced by 55.54\% for test system 2 , test system 3 , and test system 4 compared to test system 1 . In this case, the contribution of power generation from wind power plants for Test system 2 and Test system 4 are $12.25 \%$ and 54.12\% of the total generation, respectively. In addition, the contribution of power generation from solar PV for Test system 2 and Test system 3 are $41.69 \%$ and $53.93 \%$ of the total generation, respectively. 
Table 12. Optimal settings of dependent and control variables for case 2 for all test systems using EO.

\begin{tabular}{|c|c|c|c|c|c|c|}
\hline Parameters & Min & $\operatorname{Max}$ & Test System 1 & Test System 2 & Test System 3 & Test System 4 \\
\hline PG2 (MW) & 20 & 80 & 67.52765352 & 47.15393481 & 46.93784062 & 46.74579811 \\
\hline PG5 (MW) & 15 & 50 & 49.99976843 & 49.99997692 & 48.55695793 & 49.63943974 \\
\hline PG8 (MW) & 10 & 35 & 34.99979715 & 34.99785564 & 35.00000000 & 34.99981323 \\
\hline PG11 (MW) & 10 & 30 & 30.00000000 & 13.08937369 & 24.11263394 & 28.93951933 \\
\hline PG13 (MW) & 10 & 40 & 39.99994042 & 39.97364116 & 38.90979918 & 31.15977654 \\
\hline PG24 (MW) & 10 & 30 & & 29.67649489 & 20.72363213 & 13.68967898 \\
\hline PG30 (MW) & 10 & 40 & & 22.06349364 & 22.1793691 & 32.00183302 \\
\hline V1 (p.u.) & 0.95 & 1.1 & 1.061391900 & 1.035577033 & 1.017785294 & 1.007633877 \\
\hline V2 (p.u.) & 0.95 & 1.1 & 1.055299891 & 1.03014784 & 1.009596473 & 0.99225379 \\
\hline V5 (p.u.) & 0.95 & 1.1 & 1.036061646 & 0.975474909 & 0.982885915 & 0.966515297 \\
\hline V8 (p.u.) & 0.95 & 1.1 & 1.042336524 & 0.994262522 & 0.996877809 & 0.970873143 \\
\hline V11 (p.u.) & 0.95 & 1.1 & 1.056098162 & 0.99155371 & 1.066472978 & 1.018197794 \\
\hline V13 (p.u.) & 0.95 & 1.1 & 1.061630874 & 1.045591502 & 1.053301428 & 0.990382535 \\
\hline V24 (p.u.) & 0.95 & 1.1 & & 0.994310052 & 1.023161602 & 1.006430427 \\
\hline V30 (p.u.) & 0.95 & 1.1 & & 0.976743321 & 0.962066536 & 0.995194145 \\
\hline QC10 (MVAr) & 0 & 5 & 4.194820255 & 0.691891638 & 0.00000000 & 2.28917862 \\
\hline QC12 (MVAr) & 0 & 5 & 0.527663733 & 3.89808945 & 4.781805725 & 0.003693677 \\
\hline QC15 (MVAr) & 0 & 5 & 4.925786364 & 0.093781976 & 4.681393138 & 3.767863825 \\
\hline QC17 (MVAr) & 0 & 5 & 4.982842903 & 2.766984513 & 4.998326488 & 4.887538377 \\
\hline QC20 (MVAr) & 0 & 5 & 4.671024822 & 4.426843395 & 4.610963598 & 5.000000000 \\
\hline QC21 (MVAr) & 0 & 5 & 4.976075346 & 1.329009086 & 4.940763823 & 2.759967479 \\
\hline QC23 (MVAr) & 0 & 5 & 2.74762835 & 3.54838243 & 0.002439547 & 4.271161763 \\
\hline QC24 (MVAr) & 0 & 5 & 4.992557282 & 0.606928317 & 0.970384621 & 2.50397663 \\
\hline QC29 (MVAr) & 0 & 5 & 2.088379542 & 4.949034272 & 0.000438444 & 2.957731038 \\
\hline T11 (p.u.) & 0.9 & 1.1 & 1.045594251 & 0.951879814 & 0.938502294 & 0.940072546 \\
\hline T12 (p.u.) & 0.9 & 1.1 & 0.921878284 & 0.962206441 & 1.096587454 & 0.919312335 \\
\hline T15 (p.u.) & 0.9 & 1.1 & 1.00248085 & 1.099174642 & 1.018026147 & 1.023627655 \\
\hline T36 (p.u.) & 0.9 & 1.1 & 0.972355171 & 0.92579926 & 1.099689643 & 1.060629423 \\
\hline PG1 (MW) & 50 & 200 & 64.09434175 & 50.00003511 & 50.00023516 & 50.00000501 \\
\hline QG1 (MVAr) & -20 & 150 & -5.544691231 & 0.054641352 & -1.33241509 & 18.58616272 \\
\hline QG2 (MVAr) & -20 & 60 & 6.45002148 & 47.44923402 & 4.202024706 & 1.97952536 \\
\hline QG5 (MVAr) & -15 & 62.5 & 21.67156016 & -1.442938766 & 13.43474762 & 19.83503047 \\
\hline QG8 (MVAr) & -15 & 48 & 27.29675405 & 23.11453954 & 7.583267029 & 12.95707181 \\
\hline QG11 (MVAr) & -10 & 40 & 11.72500454 & -6.137543909 & 13.66528344 & 1.654000716 \\
\hline QG13 (MVAr) & -15 & 44 & 9.840166661 & 39.23629311 & 21.68524583 & 6.151027816 \\
\hline QG24 (MVAr) & -15 & 44 & & 1.089772208 & 24.29742231 & 20.10756016 \\
\hline QG 30 (MVAr) & -15 & 44 & & -13.49116551 & 0.162345045 & 0.721702425 \\
\hline$V D$ (p.u.) & & & 0.90040310 & 0.298468513 & 0.404641642 & 0.391340877 \\
\hline$F C(\$ / \mathrm{h})$ & & & 944.2808599 & 354.7638857 & 354.038595 & 353.3864113 \\
\hline$P_{\text {loss }}(\mathrm{MW})$ & & & 3.22150126 & 3.554805885 & 3.020468191 & 3.775864192 \\
\hline$E($ ton $/ \mathrm{h})$ & & & 0.204818699 & 0.091061921 & 0.091060623 & 0.091060048 \\
\hline$T C(\$ / h)$ & & & & 877.5739313 & 865.4758094 & 867.8663197 \\
\hline$C_{T}^{W}(\$ / h)$ & & & & 108.3986993 & & 514.4799085 \\
\hline$C_{T}^{P V}(\$ / \mathrm{h})$ & & & & 414.4113463 & 511.4372144 & \\
\hline$f_{o}($ ton $/ \mathrm{h})$ & & & 0.204818699 & 0.091061921 & 0.091060623 & 0.091060048 \\
\hline
\end{tabular}




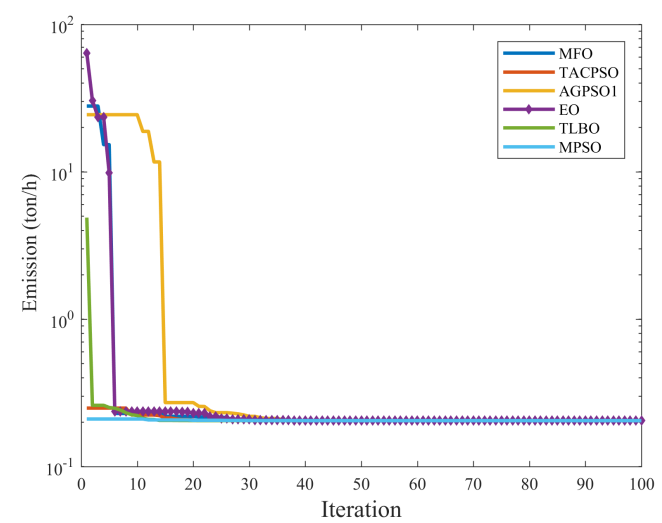

(a) Comparative convergence curves.

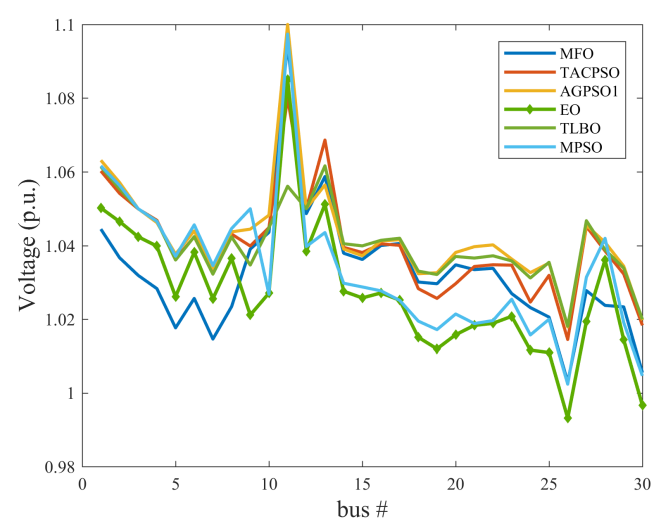

(b) Voltage profile.

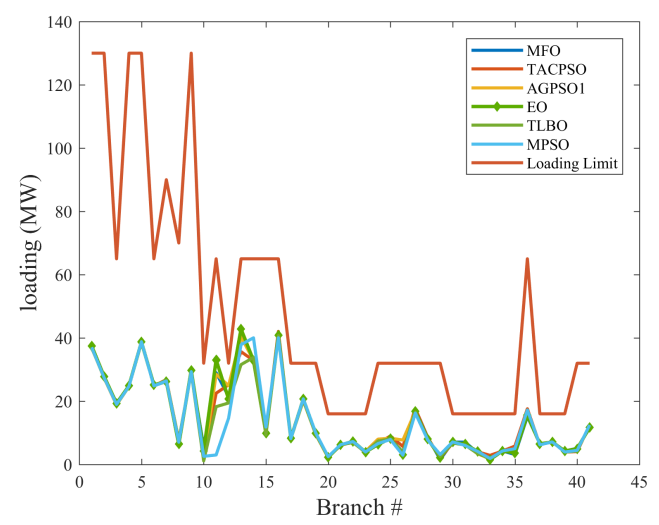

(c) Loading profile.

Figure 8. Comparative convergence, voltage and loading Profiles for case 2 for all test systems.

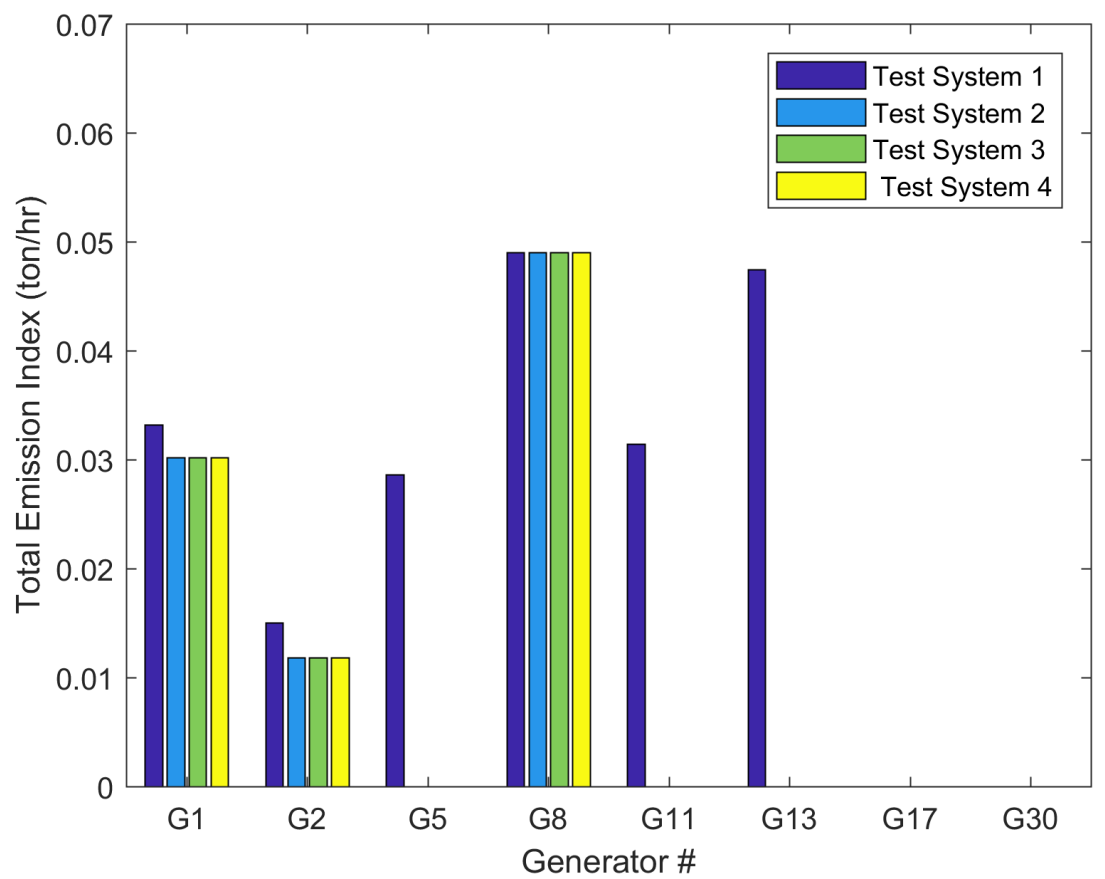

Figure 9. Total Emission index (ton/hr) of case 2 for all test systems using EO. 
Table 13 presents the results of the EO and other methods for test system 1 with the minimization of emission index. For example, the objective function of case 2 for EO was 0.204819 ton/h compared to 0.204862 ton/h and 0.204885 ton/h for MFO [47] and TLBO [46] algorithms, respectively.

Table 13. Results of EO and other methods of case 2 for Test system 1.

\begin{tabular}{ccccccc}
\hline & MFO & TACPSO & AGPSO1 & TLBO & EO & MPSO \\
\hline$V D($ p.u. $)$ & 0.702001 & 0.856848 & 0.921129 & 0.541768425 & 0.900403 & 0.661504 \\
$F C(\$ / \mathrm{h})$ & 944.3434 & 944.6554 & 944.3977 & 944.6873755 & 944.2809 & 944.4382 \\
$P_{\text {loss }}(\mathrm{MW})$ & 3.356033 & 3.286856 & 3.235581 & 3.336091467 & 3.221501 & 3.267419 \\
$E($ ton $/ \mathrm{h})$ & 0.204862 & 0.204839 & 0.204823 & 0.204854728 & 0.204819 & 0.204833 \\
\hline$f_{o}($ ton $/ \mathrm{h})$ & 0.204862 & 0.204839 & 0.204823 & 0.204854728 & 0.204819 & 0.204833 \\
\hline
\end{tabular}

Table 14 summarizes the statistical results for the present case. It can be found from Table 14 that the EO provides the smallest best, standard deviation, and median than other methods.

Table 14. Summary of the statistical analysis of case 2 for Test system 1.

\begin{tabular}{ccccc}
\hline & Best & Worst & Mean & Std Dev \\
\hline MFO & 0.204862 & 0.204997 & 0.20495 & $4.15 \times 10^{-5}$ \\
TACPSO & 0.204839 & 0.205089 & 0.204943 & $9.14 \times 10^{-5}$ \\
AGPSO1 & 0.204823 & 0.204999 & 0.204921 & $5.14 \times 10^{-5}$ \\
TLBO & 0.204855 & 0.204931 & 0.204892 & $2.43 \times 10^{-5}$ \\
EO & 0.204819 & 0.204878 & 0.204834 & $1.78 \times 10^{-5}$ \\
MPSO & 0.204833 & 0.20497 & 0.204934 & $5.44 \times 10^{-5}$ \\
\hline
\end{tabular}

\subsubsection{Minimization of the Total Cost of Generating Units}

The comparative convergence characteristics, loading profiles, and loss profiles for test system 1 for the EO and other optimization techniques are presented in Figure 10. As observed in Figure 10, the voltage and loading profiles are kept within the acceptable ranges and the EO gives the best convergence characteristics compared to other methods. The optimal results of the EO and other techniques for test system 1 are summarized in Table 15. From Table 15, the EO leads to 800.4486 \$/h total cost of generators which is better than the total cost obtained by the other compared methods. From Figure 10b,c, it can be found that even though EO can obtain the minimum value of the total cost of power generation, the loading of the transmission lines is more than other methods and voltage deviation of $\mathrm{EO}$ is higher than other optimization techniques.

Table 15. Results of EO and other methods of case 3 for Test system 1.

\begin{tabular}{ccccccc}
\hline & MFO & TACPSO & AGPSO1 & TLBO & EO & MPSO \\
\hline$V D($ p.u. $)$ & 0.740965 & 0.845878 & 0.761669 & 0.811019872 & 0.865075 & 0.877139 \\
$F C(\$ / \mathrm{h})$ & 800.8283 & 800.5201 & 800.5595 & 800.616176 & 800.4486 & 800.5346 \\
$P_{\text {loss }}(\mathrm{MW})$ & 9.134902 & 9.02898 & 9.040104 & 8.97569702 & 9.041464 & 9.059254 \\
$E($ ton $/ \mathrm{h})$ & 0.366492 & 0.366315 & 0.365967 & 0.363482104 & 0.367478 & 0.366949 \\
\hline$f_{o}(\$ / \mathrm{h})$ & 800.8283 & 800.5201 & 800.5595 & 800.616176 & 800.4486 & 800.5346 \\
\hline
\end{tabular}




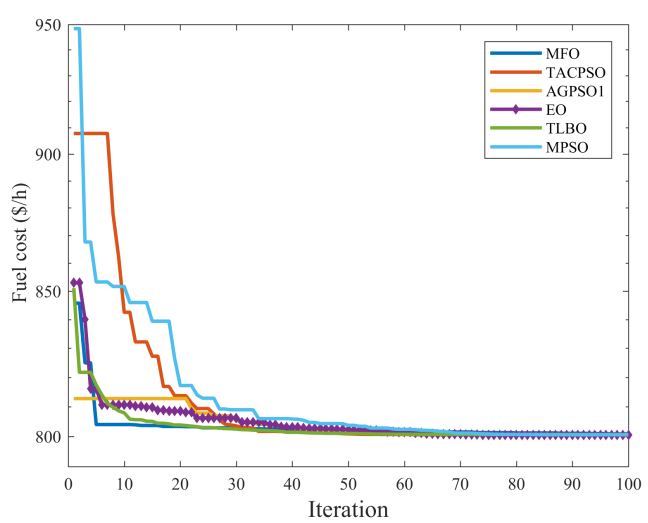

(a) Comparative convergence curves.

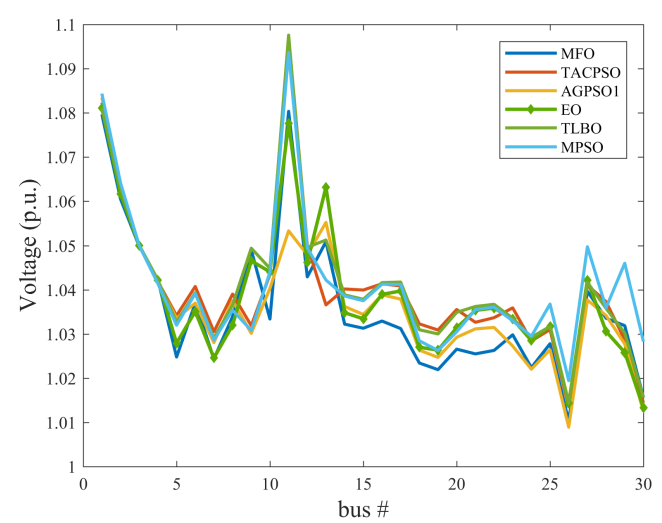

(b) Voltage profile.

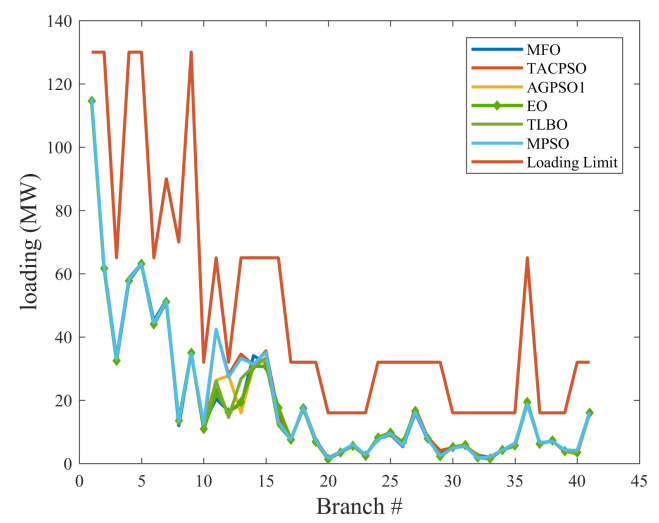

(c) Loading profile.

Figure 10. Comparative convergence, voltage and loading Profiles for case 3 for all test systems.

The statistical results yielded by the EO and other optimization techniques are given in Table 16.

Table 16. Summary of the statistical analysis of case 3 for Test system 1.

\begin{tabular}{ccccc}
\hline & Best & Worst & Mean & Std Dev \\
\hline MFO & 800.8283 & 802.8078 & 801.5102 & 0.72899 \\
TACPSO & 800.5201 & 804.0448 & 800.6766 & 1.305504 \\
AGPSO1 & 800.5595 & 802.1145 & 800.7023 & 0.453581 \\
TLBO & 800.6162 & 802.225 & 800.8366 & 0.471362 \\
EO & 800.4486 & 800.646 & 800.4793 & 0.057894 \\
MPSO & 800.5346 & 804.6442 & 801.1155 & 1.810857 \\
\hline
\end{tabular}

From Table 17 and Figure 11, it can be observed that the total cost of generating units for test system 2 , test system 3, and test system 4 declined by $3.54 \%, 3.47 \%$, and $2.91 \%$, respectively, compared to test system 1. In this case, as shown in Table 17; the contribution of power generation from wind power plants for Test system 2 and Test system 4 are $9.58 \%$ and $35.68 \%$ of the total generation, respectively. Moreover, the contribution of power generation from solar PV for Test system 2 and Test system 3 are $21.33 \%$ and $41.17 \%$ of the total generation, respectively. 
Table 17. Optimal settings of dependent and control variables for case 3 for all test systems using EO.

\begin{tabular}{|c|c|c|c|c|c|c|}
\hline Parameters & Min & $\operatorname{Max}$ & Test System 1 & Test System 2 & Test System 3 & Test System 4 \\
\hline PG2 (MW) & 20 & 80 & 48.74605575 & 45.18712121 & 21.21838812 & 38.17119779 \\
\hline PG5 (MW) & 15 & 50 & 21.4315437 & 15.00195728 & 15.40668673 & 19.095538 \\
\hline PG8 (MW) & 10 & 35 & 21.18353338 & 29.97018297 & 15.60913424 & 10.08641797 \\
\hline PG11 (MW) & 10 & 30 & 11.52952165 & 13.07275916 & 29.402226 & 20.7452611 \\
\hline PG13 (MW) & 10 & 40 & 12.0107829 & 19.71387022 & 30.51540057 & 17.9328134 \\
\hline PG24 (MW) & 10 & 30 & & 27.19702311 & 26.3304831 & 25.32965431 \\
\hline PG30 (MW) & 10 & 40 & & 14.74139467 & 17.72178713 & 20.28023584 \\
\hline V1 (p.u.) & 0.95 & 1.1 & 1.081191705 & 1.022713246 & 1.02314065 & 1.059255936 \\
\hline V2 (p.u.) & 0.95 & 1.1 & 1.063110135 & 1.006065736 & 1.008766945 & 1.043719467 \\
\hline V5 (p.u.) & 0.95 & 1.1 & 1.032684857 & 0.956733982 & 0.961917138 & 1.009460201 \\
\hline V8 (p.u.) & 0.95 & 1.1 & 1.036543249 & 0.994159517 & 0.985269141 & 1.02095678 \\
\hline V11 (p.u.) & 0.95 & 1.1 & 1.097591909 & 1.012587735 & 1.049992902 & 1.0845661 \\
\hline V13 (p.u.) & 0.95 & 1.1 & 1.051244633 & 1.054638289 & 1.011514979 & 1.046208927 \\
\hline V24 (p.u.) & 0.95 & 1.1 & & 1.035583887 & 1.011800496 & 1.043496784 \\
\hline V30 (p.u.) & 0.95 & 1.1 & & 0.950000000 & 0.996591531 & 1.048407181 \\
\hline QC10 (MVAr) & 0 & 5 & 2.971616423 & 3.739491269 & 4.902790106 & 0.325756054 \\
\hline QC12 (MVAr) & 0 & 5 & 0.655177618 & 4.809891924 & 1.662706176 & 3.06145818 \\
\hline QC15 (MVAr) & 0 & 5 & 3.197516308 & 0.002648509 & 0.249875162 & 3.301750446 \\
\hline QC17 (MVAr) & 0 & 5 & 4.723716655 & 3.279961844 & 1.827574807 & 1.707154585 \\
\hline QC20 (MVAr) & 0 & 5 & 3.650622268 & 0.917150962 & 1.107119341 & 0.418013886 \\
\hline QC21 (MVAr) & 0 & 5 & 5.000000000 & 4.948708899 & 2.08610321 & 4.893042007 \\
\hline QC23 (MVAr) & 0 & 5 & 2.498554056 & 4.535914953 & 4.240774401 & 3.58924067 \\
\hline QC24 (MVAr) & 0 & 5 & 4.985418463 & 5.000000000 & 0.00000000 & 1.169769378 \\
\hline QC29 (MVAr) & 0 & 5 & 2.584313587 & 4.144114834 & 4.95463484 & 1.500067393 \\
\hline T11 (p.u.) & 0.9 & 1.1 & 1.027284076 & 1.048412041 & 1.099843892 & 0.985023037 \\
\hline T12 (p.u.) & 0.9 & 1.1 & 0.971275895 & 0.90000000 & 0.922169184 & 0.989956238 \\
\hline T15 (p.u.) & 0.9 & 1.1 & 0.972373363 & 1.002944153 & 1.006664961 & 0.991751478 \\
\hline T36 (p.u.) & 0.9 & 1.1 & 0.9815263 & 1.059841992 & 0.944073975 & 0.971316876 \\
\hline PG1 (MW) & 50 & 200 & 177.5400261 & 125.374001 & 133.7249716 & 138.0708394 \\
\hline QG1 (MVAr) & -20 & 150 & -0.570024945 & -0.833938199 & -5.669301771 & -1.647701957 \\
\hline QG2 (MVAr) & -20 & 60 & 19.80925666 & 13.30674022 & 30.0465083 & 18.91158888 \\
\hline QG5 (MVAr) & -15 & 62.5 & 25.58480054 & 6.160576051 & 11.07617293 & 21.00268292 \\
\hline QG8 (MVAr) & -15 & 48 & 23.28431397 & 23.75265502 & 14.5584729 & 21.65678972 \\
\hline QG11 (MVAr) & -10 & 40 & 25.55139519 & 8.157153402 & 35.09222447 & 19.52230631 \\
\hline QG13 (MVAr) & -15 & 44 & 1.335643081 & 21.55072062 & 12.13070192 & 7.287213883 \\
\hline QG24 (MVAr) & -15 & 44 & & 22.34214251 & 15.27252587 & 8.101017671 \\
\hline QG 30 (MVAr) & -15 & 44 & & -5.331414964 & -8.278410983 & -1.403218975 \\
\hline$V D$ (p.u.) & & & 0.865074691 & 0.312619858 & 0.288839815 & 0.653856503 \\
\hline$F C(\$ / h)$ & & & 800.4486031 & 529.3973749 & 432.2815387 & 473.5571537 \\
\hline$P_{\text {loss }}(\mathrm{MW})$ & & & 9.041463508 & 6.858309749 & 6.529077621 & 6.311958209 \\
\hline$E($ ton $/ \mathrm{h})$ & & & 0.367478227 & 0.141650437 & 0.159248156 & 0.163097259 \\
\hline$T C(\$ / h)$ & & & & 772.2465456 & 772.7810970 & 777.3121394 \\
\hline$C_{T}^{W}(\$ / h)$ & & & & 85.46692162 & & 303.7549857 \\
\hline$C_{T}^{P V}(\$ / \mathrm{h})$ & & & & 157.3822491 & 340.4995583 & \\
\hline$f_{o}(\$ / h)$ & & & 800.4486031 & 772.2465456 & 772.7810970 & 777.3121394 \\
\hline
\end{tabular}




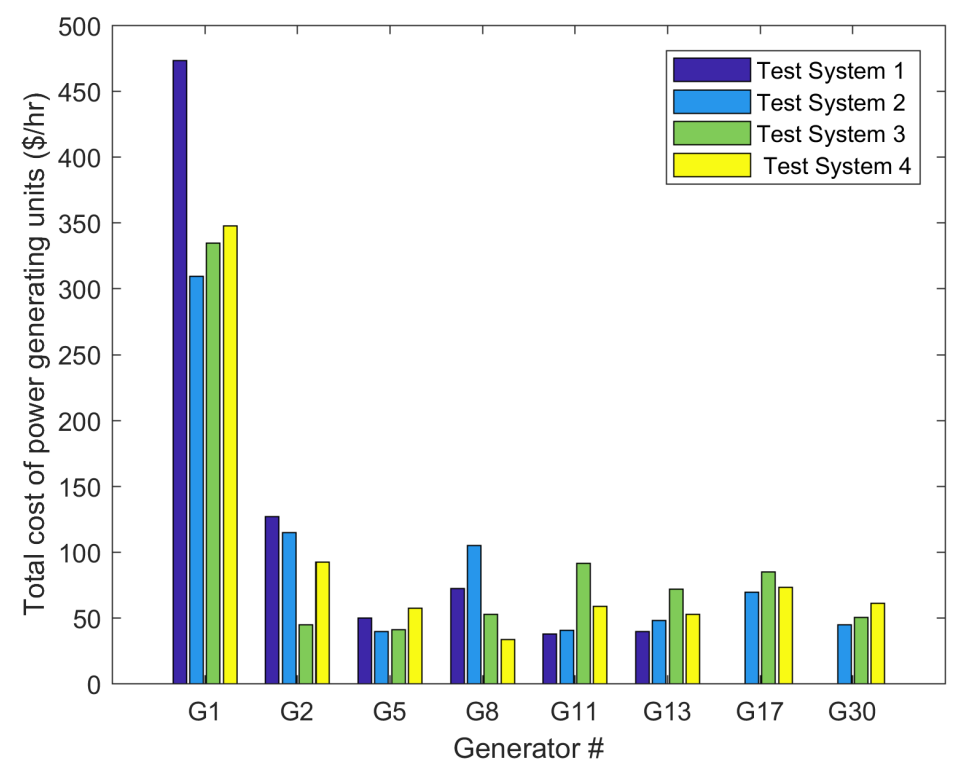

Figure 11. Total cost of generating units of case 3 for all test systems using EO.

\subsubsection{Voltage Deviation Minimization}

Figure 12 demonstrates the voltage profiles for all test systems for this case using EO. The optimal solution obtained by EO for test system 1, test system 2, test system 3, and test system 4 are tabulated in Table 18. As shown in Figure 12 and Table 18, the presence of the renewable energy resources improves the voltage profiles and reduced the voltage deviation for test system 2, test system 3 , and test system 4 by $22.46 \%, 37.39 \%$, and $29.61 \%$, respectively, compared to test system 1 . Besides, it can be observed that the power generation contribution of Test system 2 from wind, solar PV and thermal power generation are $17.57 \%, 17.87 \%$, and $64.54 \%$, respectively. With respect to Test system 3 , the contribution of power generation from solar PV and thermal power are $34.69 \%$ and $65.30 \%$, respectively. Moreover, the wind power plants of Test system 4 contribute $55.34 \%$ of the total power generation.

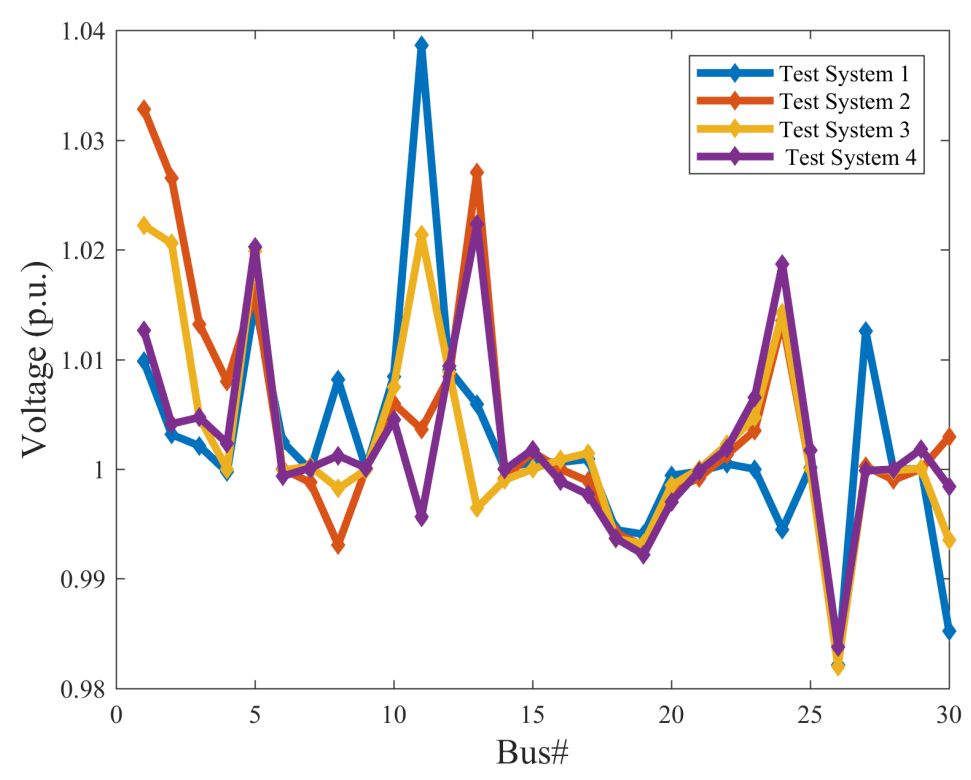

Figure 12. Voltage profiles of case 4 for all test systems using EO. 
Table 18. Optimal settings of dependent and control variables for case 4 for all test systems using EO.

\begin{tabular}{|c|c|c|c|c|c|c|}
\hline Parameters & Min & $\operatorname{Max}$ & Test System 1 & Test System 2 & Test System 3 & Test System 4 \\
\hline PG2 (MW) & 20 & 80 & 70.18121441 & 35.84850999 & 73.22346542 & 42.82238053 \\
\hline PG5 (MW) & 15 & 50 & 25.52703119 & 20.27116158 & 33.56379457 & 47.02961201 \\
\hline PG8 (MW) & 10 & 35 & 28.87890546 & 17.61889372 & 18.04097353 & 33.85695266 \\
\hline PG11 (MW) & 10 & 30 & 29.30401557 & 24.63092203 & 10.13966121 & 14.67013887 \\
\hline PG13 (MW) & 10 & 40 & 27.92172576 & 15.28698582 & 21.57955174 & 39.93831108 \\
\hline PG24 (MW) & 10 & 30 & & 16.34156919 & 10.07569951 & 28.44997135 \\
\hline PG30 (MW) & 10 & 40 & & 26.43024961 & 24.9797807 & 28.73744876 \\
\hline V1 (p.u.) & 0.95 & 1.1 & 1.009811989 & 1.032801388 & 1.022207169 & 1.012647301 \\
\hline V2 (p.u.) & 0.95 & 1.1 & 1.003153500 & 1.026505843 & 1.020581934 & 1.004121334 \\
\hline V5 (p.u.) & 0.95 & 1.1 & 1.015213206 & 1.016105476 & 1.019877057 & 1.020275353 \\
\hline V8 (p.u.) & 0.95 & 1.1 & 1.008124785 & 0.993094249 & 0.998231049 & 1.001227396 \\
\hline V11 (p.u.) & 0.95 & 1.1 & 1.038640051 & 1.003641057 & 1.02134836 & 0.99563608 \\
\hline V13 (p.u.) & 0.95 & 1.1 & 1.005894818 & 1.02703208 & 0.996453698 & 1.022325949 \\
\hline V24 (p.u.) & 0.95 & 1.1 & & 1.013528762 & 1.014235434 & 1.018656779 \\
\hline V30 (p.u.) & 0.95 & 1.1 & & 1.002929877 & 0.993533496 & 0.998414844 \\
\hline QC10 (MVAr) & 0 & 5 & 4.999434200 & 1.057601365 & 4.449085771 & 1.224696754 \\
\hline QC12 (MVAr) & 0 & 5 & 4.602398118 & 2.55410853 & 4.99999823 & 2.663316679 \\
\hline QC15 (MVAr) & 0 & 5 & 4.960424711 & 4.999607248 & 1.610176653 & 3.415934203 \\
\hline QC17 (MVAr) & 0 & 5 & 0.01181544 & 0.217347144 & 1.996228043 & 0.019033266 \\
\hline QC20 (MVAr) & 0 & 5 & 4.996883927 & 4.92956648 & 4.978309396 & 4.994054795 \\
\hline QC21 (MVAr) & 0 & 5 & 4.956429831 & 1.646590977 & 0.034134918 & 4.819904248 \\
\hline QC23 (MVAr) & 0 & 5 & 4.972309922 & 0.427048793 & 1.956957345 & 1.039869954 \\
\hline QC24 (MVAr) & 0 & 5 & 4.980435681 & 2.406207968 & 4.614781826 & 0.613094925 \\
\hline QC29 (MVAr) & 0 & 5 & 2.520824595 & 1.71349761 & 3.890942901 & 3.740081954 \\
\hline T11 (p.u.) & 0.9 & 1.1 & 1.056622635 & 1.012874303 & 1.035801681 & 1.002332018 \\
\hline T12 (p.u.) & 0.9 & 1.1 & 0.901402975 & 0.900602964 & 0.902285005 & 0.901103808 \\
\hline T15 (p.u.) & 0.9 & 1.1 & 0.981060937 & 1.013218403 & 0.960787866 & 0.998733169 \\
\hline T36 (p.u.) & 0.9 & 1.1 & 0.966944023 & 0.987755959 & 0.989855906 & 0.98143194 \\
\hline PG1 (MW) & 50 & 200 & 108.1160533 & 133.9296827 & 97.60688393 & 51.45175998 \\
\hline QG1 (MVAr) & -20 & 150 & -19.10239902 & -19.59757178 & -19.11821266 & -0.518817877 \\
\hline QG2 (MVAr) & -20 & 60 & -14.85253038 & 31.85856685 & 18.90601653 & -16.64972076 \\
\hline QG5 (MVAr) & -15 & 62.5 & 57.49581183 & 49.60698522 & 51.42002978 & 56.50571855 \\
\hline QG8 (MVAr) & -15 & 48 & 45.23093447 & 11.80532985 & 26.14354452 & 31.44056819 \\
\hline QG11 (MVAr) & -10 & 40 & 20.12674964 & 2.380585374 & 10.62092072 & -1.914317997 \\
\hline QG13 (MVAr) & -15 & 44 & -1.74441538 & 13.80317636 & -8.465359993 & 10.55389137 \\
\hline QG24 (MVAr) & -15 & 44 & & 14.86630972 & 15.99035449 & 13.88576475 \\
\hline QG 30 (MVAr) & -15 & 44 & & -4.888937122 & -7.68659143 & -7.960636408 \\
\hline$V D$ (p.u.) & & & 0.088397534 & 0.08005165 & 0.064632335 & 0.07266919 \\
\hline$F C(\$ / h)$ & & & 848.7795548 & 480.1984844 & 514.2584395 & 339.455916 \\
\hline$P_{\text {loss }}(\mathrm{MW})$ & & & 6.528945889 & 6.957974748 & 5.809810669 & 3.556575273 \\
\hline$E($ ton $/ \mathrm{h})$ & & & 0.240505607 & 0.155665569 & 0.119726864 & 0.091393798 \\
\hline$T C(\$ / h)$ & & & & 787.9483007 & 810.1863986 & 861.8303756 \\
\hline$C_{T}^{W}(\$ / h)$ & & & & 164.0403370 & & 522.3744597 \\
\hline$C_{T}^{P V}(\$ / \mathrm{h})$ & & & & 143.7094792 & 295.9279591 & \\
\hline$f_{o}$ (p.u.) & & & 0.088397534 & 0.080051650 & 0.064632335 & 0.07266919 \\
\hline
\end{tabular}

It is clear from Table 19; the minimum best, standard deviation, and median are obtained by the EO.

From Figure 13, the voltage and loading profiles for this case for all optimization methods obey the constraints of voltages at load buses and transmission line loading. It can also be observed that the EO convergence characteristic outperforms the convergence characteristics of other methods. The results of EO and other methods for test system 1 are given in Table 20. From Figure 13b,c and Table 20, it can be seen that $\mathrm{EO}$ achieves the minimum emission index while minimizing the objective function of 
voltage deviation. In addition, $\mathrm{EO}$ and MFO can obtain the lowest real power loss at $6.528 \mathrm{MW}$ and $5.965 \mathrm{MW}$, respectively. Nevertheless, MPSO, TLBO, TACPSO, and ACPSO1 obtain lower fuel cost in comparison to EO.

Table 19. Summary of the statistical analysis of case 4 for Test system 1 .

\begin{tabular}{ccccc}
\hline & Best & Worst & Mean & Std Dev \\
\hline MFO & 0.100862 & 0.137899 & 0.117452 & 0.011555 \\
TACPSO & 0.092725 & 0.177792 & 0.116202 & 0.025827 \\
AGPSO1 & 0.102816 & 0.144276 & 0.131944 & 0.015650 \\
TLBO & 0.103244 & 0.152343 & 0.112717 & 0.015185 \\
EO & 0.088398 & 0.097568 & 0.092814 & 0.002809 \\
MPSO & 0.093414 & 0.202628 & 0.124612 & 0.038641 \\
\hline
\end{tabular}

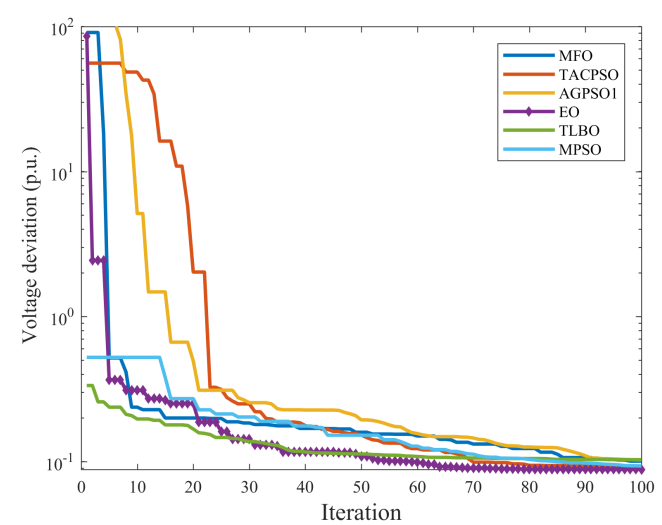

(a) Comparative convergence curves.

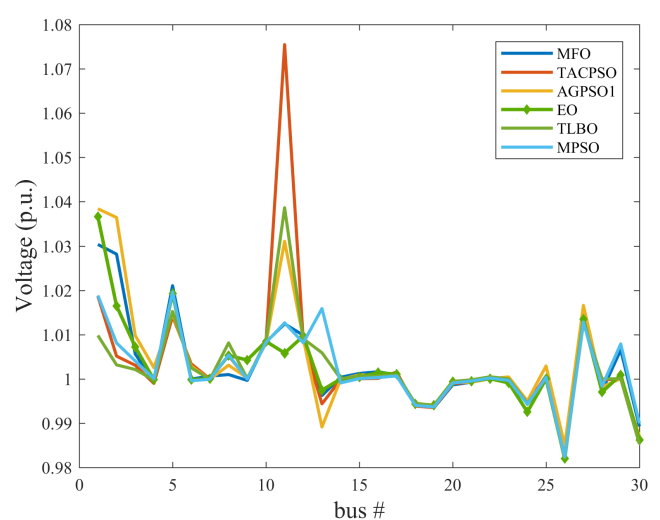

(b) Voltage profile.

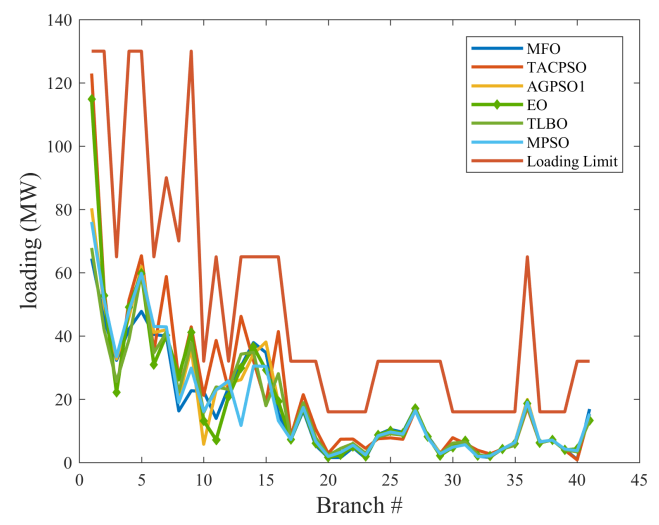

(c) Loading profile.

Figure 13. Comparative convergence, voltage and loading profiles for case 4 for all test systems.

Table 20. Results of EO and other methods of case 4 for Test system 1.

\begin{tabular}{ccccccc}
\hline & MFO & TACPSO & AGPSO1 & TLBO & EO & MPSO \\
\hline$V D($ p.u. $)$ & 0.100862 & 0.092725 & 0.102816 & 0.103243 & 0.088398 & 0.093414 \\
$F C(\$ /$ h) & 901.7397 & 852.0642 & 834.1079 & 829.58791 & 848.7796 & 841.3429 \\
$P_{\text {loss }}(\mathrm{MW})$ & 5.965677 & 9.980964 & 7.492151 & 8.391654 & 6.528946 & 7.564352 \\
$E$ (ton $/$ h) & 0.248497 & 0.359732 & 0.273799 & 0.337325 & 0.240506 & 0.275282 \\
\hline$f_{o}$ (p.u.) & 0.100862 & 0.092725 & 0.102816 & 0.103243 & 0.088398 & 0.093414 \\
\hline
\end{tabular}


6.1.5. Case 5: Minimization of the Total Cost of the Generating Units, Voltage Deviation, Real Power Loss, and Emission Index

It is clear from Figure 14 that the EO has the best convergence characteristics compared to the other optimization algorithms and the voltage and loading profiles for all algorithm ranges within the allowable limits. The results of EO and other methods for test system 1 of this case are shown in Table 21. It is clear from Figure 14b,c and Table 21 that while EO achieves the minimum value of voltage deviation and fuel cost in comparison to other methods, other optimization techniques obtain lower values of emission index and real power loss than EO.

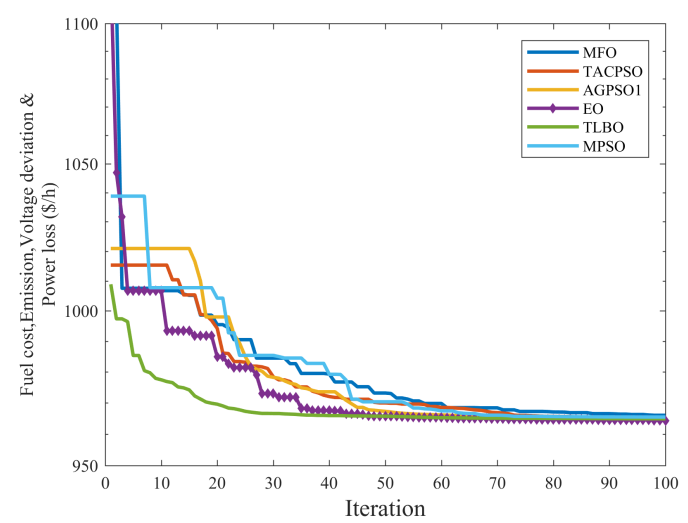

(a) Comparative convergence curves.

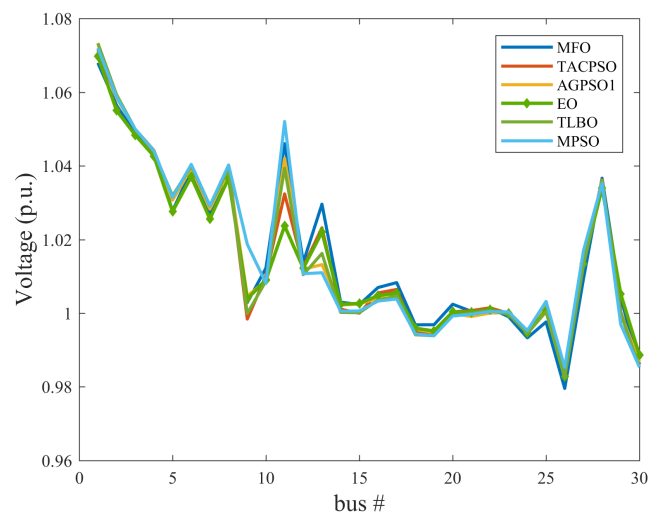

(b) Voltage profile.

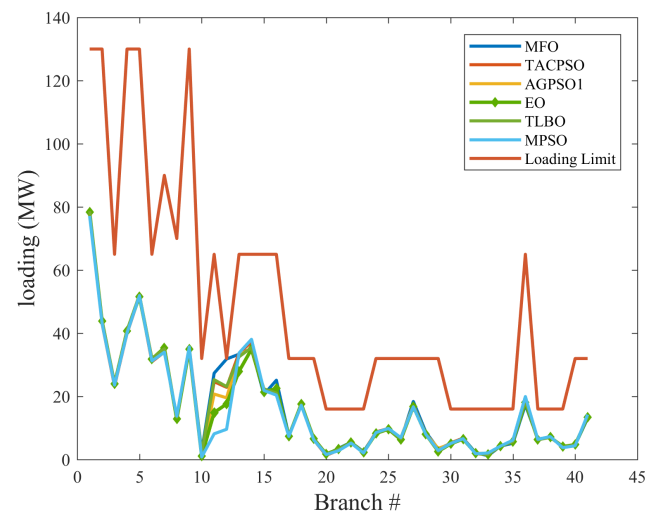

(c) Loading profile.

Figure 14. Comparative convergence, voltage and loading profiles for case 5 for all Test system 1.

Table 21. Results of EO and other methods of case 5 for Test system 1.

\begin{tabular}{ccccccc}
\hline & MFO & TACPSO & AGPSO1 & TLBO & EO & MPSO \\
\hline$V D($ p.u. $)$ & 0.312222 & 0.301092 & 0.2979 & 0.292001838 & 0.291525 & 0.315655 \\
$F C(\$ / \mathrm{h})$ & 832.131 & 833.4427 & 831.8455 & 831.251448 & 829.9924 & 833.2358 \\
$P_{\text {loss }}(\mathrm{MW})$ & 5.569804 & 5.471244 & 5.542919 & 5.575077257 & 5.604236 & 5.490564 \\
$E($ ton $/ \mathrm{h})$ & 0.250434 & 0.249973 & 0.251339 & 0.252691258 & 0.253454 & 0.249919 \\
\hline$f_{o}(\$ / \mathrm{h})$ & 965.9816 & 964.8825 & 964.8211 & 964.8363202 & 964.2232 & 965.4054 \\
\hline
\end{tabular}

The statistical analysis of the EO and other methods for test system 1 is given in Table 22. As shown in the table, the EO gives the minimum best, median and standard deviation. 
Table 22. Summary of the statistical analysis of case 5 for Test system 1.

\begin{tabular}{ccccc}
\hline & Best & Worst & Mean & Std dev \\
\hline MFO & 965.9816 & 970.7178 & 968.0071 & 1.616872 \\
TACPSO & 964.8825 & 968.5757 & 965.8415 & 1.251791 \\
AGPSO1 & 964.8211 & 967.8093 & 965.6185 & 0.874411 \\
TLBO & 964.8363 & 968.0825 & 966.0087 & 1.105687 \\
EO & 964.2232 & 966.3464 & 964.5618 & 0.655197 \\
MPSO & 965.4054 & 978.9642 & 966.4455 & 4.054598 \\
\hline
\end{tabular}

It is clear from Figure 15 and Table 23 that the objective function for this case for test system 2, test system 3, and test system 4 dropped by 3.90\%,7.77\%, and $7.84 \%$, respectively compared to test system 1. It is found from Table 23 that the real power loss for test system 2, test system 3, and test system 4 dropped by $30.94 \%, 20.75 \%$, and $46.06 \%$, respectively compared to test system 1 . It can be noted in Figure 15 that the contribution of power generation from wind for Test system 2 and Test system 4 are $15.67 \%$ and $49.37 \%$ of the total power generation, respectively. While the solar PV contributes $33.36 \%$ and $44.69 \%$ of the total power for test system 2 and test system 3, respectively. Moreover, it is observed from Table 23 that emission index for test system 2, test system 3, and test system 4 dropped by $61.24 \%, 54.91 \%$, and $58.58 \%$, respectively compared to test system 1 .

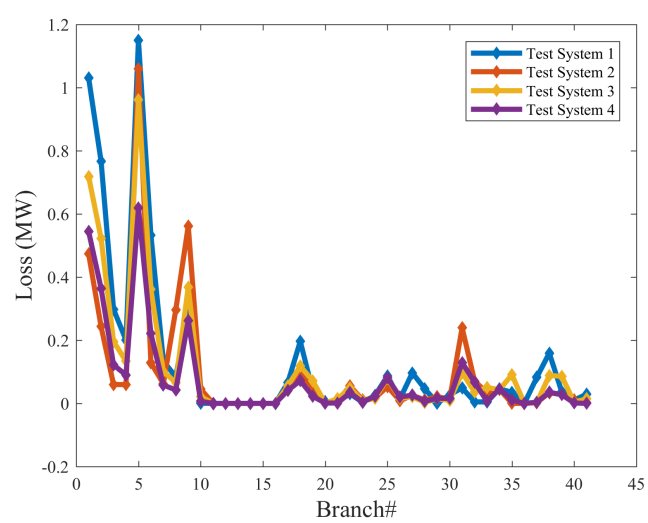

(a) Loss profile.

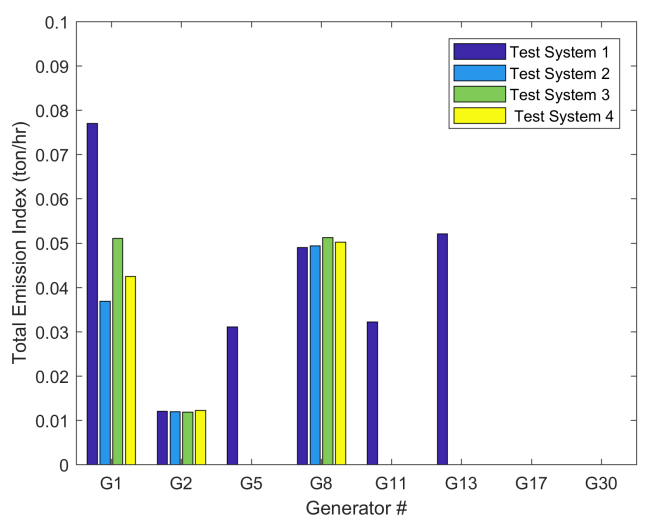

(c) Total emission index.

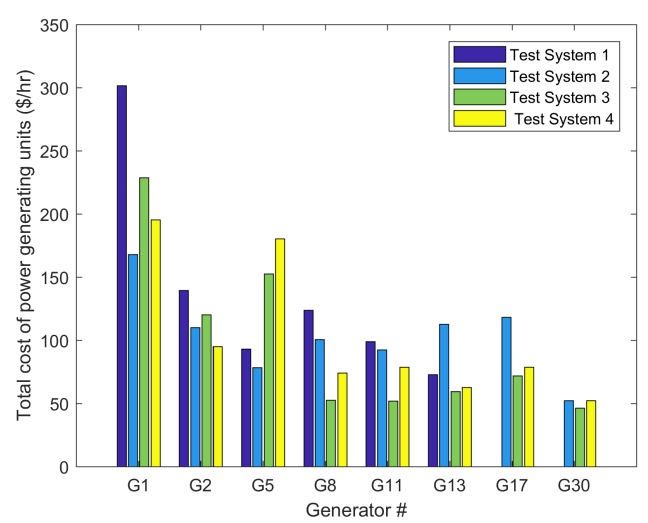

(b) Total cost of generating units.

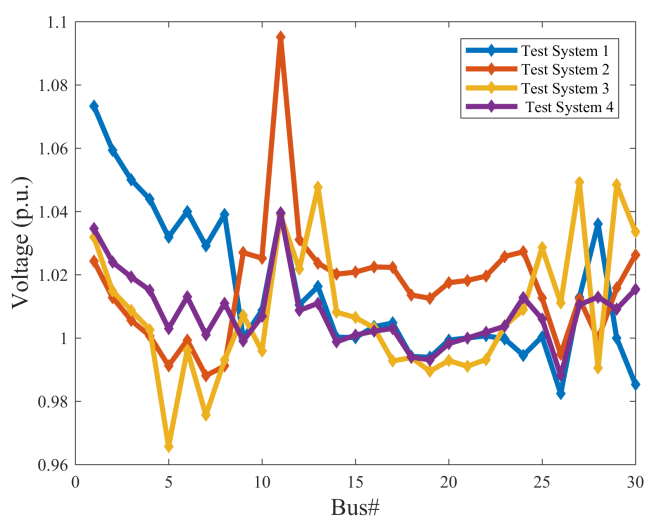

(d) Voltage profiles.

Figure 15. Total cost of generating units, total emission index, voltage and loss profiles of case 5 for all test systems. 
Table 23. Optimal settings of dependent and control variables for case 5 for all test systems using EO.

\begin{tabular}{|c|c|c|c|c|c|c|}
\hline Parameters & Min & Max & Test System 1 & Test System 2 & Test System 3 & Test System 4 \\
\hline PG2 (MW) & 20 & 80 & 52.34900301 & 43.76198174 & 46.85392201 & 39.04580002 \\
\hline PG5 (MW) & 15 & 50 & 31.41892625 & 25.13957863 & 41.57764325 & 49.63341394 \\
\hline PG8 (MW) & 10 & 35 & 34.99720302 & 28.83722988 & 15.57308058 & 21.63539649 \\
\hline PG11 (MW) & 10 & 30 & 26.95716205 & 27.72005416 & 28.54767347 & 26.5299306 \\
\hline PG13 (MW) & 10 & 40 & 20.69034077 & 37.30220041 & 21.35593529 & 20.93782021 \\
\hline PG24 (MW) & 10 & 30 & & 33.41823981 & 19.87429698 & 27.03669094 \\
\hline PG30 (MW) & 10 & 40 & & 17.31391519 & 17.29441758 & 17.27175615 \\
\hline V1 (p.u.) & 0.95 & 1.1 & 1.073302714 & 1.024270078 & 1.031881955 & 1.034535652 \\
\hline V2 (p.u.) & 0.95 & 1.1 & 1.05933056 & 1.012773005 & 1.014838234 & 1.023955028 \\
\hline V5 (p.u.) & 0.95 & 1.1 & 1.031867076 & 0.991186486 & 0.965629646 & 1.002922115 \\
\hline V8 (p.u.) & 0.95 & 1.1 & 1.039079245 & 0.991138879 & 0.993005954 & 1.010973253 \\
\hline V11 (p.u.) & 0.95 & 1.1 & 1.039336016 & 1.100000000 & 1.038730973 & 1.039568814 \\
\hline V13 (p.u.) & 0.95 & 1.1 & 1.016224258 & 1.023619922 & 1.047631647 & 1.010922024 \\
\hline V24 (p.u.) & 0.95 & 1.1 & & 1.027240201 & 1.008908379 & 1.012804196 \\
\hline V30 (p.u.) & 0.95 & 1.1 & & 1.026258901 & 1.033487159 & 1.015369168 \\
\hline QC10 (MVAr) & 0 & 5 & 1.42704702 & 0.24222794 & 5.00000000 & 3.367347878 \\
\hline QC12 (MVAr) & 0 & 5 & 0.114983911 & 4.465905221 & 5.00000000 & 4.957438998 \\
\hline QC15 (MVAr) & 0 & 5 & 2.71927269 & 0.00000000 & 1.436680682 & 3.38628092 \\
\hline QC17 (MVAr) & 0 & 5 & 4.777257639 & 4.971408287 & 0.00000000 & 4.999449612 \\
\hline QC20 (MVAr) & 0 & 5 & 4.891165116 & 4.864936873 & 5.00000000 & 4.836689278 \\
\hline QC21 (MVAr) & 0 & 5 & 4.917867343 & 4.114355205 & 4.252301174 & 2.729537609 \\
\hline QC23 (MVAr) & 0 & 5 & 4.944826897 & 4.912774176 & 0.00000000 & 1.224294666 \\
\hline QC24 (MVAr) & 0 & 5 & 4.999139393 & 3.383242169 & 2.790571405 & 4.901232863 \\
\hline QC29 (MVAr) & 0 & 5 & 2.36221935 & 0.622641699 & 5.00000000 & 0.478740405 \\
\hline T11 (p.u.) & 0.9 & 1.1 & 1.098277898 & 1.041847001 & 0.996768732 & 1.070613035 \\
\hline T12 (p.u.) & 0.9 & 1.1 & 0.937769396 & 0.906411875 & 1.061448786 & 0.920185016 \\
\hline T15 (p.u.) & 0.9 & 1.1 & 1.02148431 & 0.939592837 & 0.983885511 & 0.995441894 \\
\hline T36 (p.u.) & 0.9 & 1.1 & 1.002153866 & 0.991006369 & 0.904079564 & 0.993400466 \\
\hline PG1 (MW) & 50 & 200 & 122.5915999 & 73.77703 & 96.76396309 & 84.33186618 \\
\hline QG1 (MVAr) & -20 & 150 & 0.44760914 & 4.980415704 & 11.6826979 & -1.350997342 \\
\hline QG2 (MVAr) & -20 & 60 & 13.45186855 & 10.12960773 & 16.17020662 & 8.009356413 \\
\hline QG5 (MVAr) & -15 & 62.5 & 22.96436543 & 30.2545861 & -0.480850004 & 19.94798351 \\
\hline QG8 (MVAr) & -15 & 48 & 25.09929462 & 4.325252485 & 25.37843413 & 24.0097914 \\
\hline QG11 (MVAr) & -10 & 40 & 20.42841833 & 39.34377358 & 16.58858651 & 20.9433804 \\
\hline QG13 (MVAr) & -15 & 44 & 4.484753294 & -4.510415315 & 19.67801235 & 1.913484758 \\
\hline QG24 (MVAr) & -15 & 44 & & -1.505790029 & 2.129992746 & 2.949992903 \\
\hline QG 30 (MVAr) & -15 & 44 & & 3.138390036 & -7.584798837 & 0.645488754 \\
\hline$V D$ (p.u.) & & & 0.291524702 & 0.340717958 & 0.287869453 & 0.142747756 \\
\hline$F C(\$ / \mathrm{h})$ & & & 829.9923878 & 378.7198323 & 401.6872426 & 364.5623372 \\
\hline$P_{\text {loss }}(\mathrm{MW})$ & & & 5.604235892 & 3.870229887 & 4.440932453 & 3.022674546 \\
\hline$E($ ton $/ \mathrm{h})$ & & & 0.253453881 & 0.098214148 & 0.114249163 & 0.104949647 \\
\hline TC $(\$ / h)$ & & & & 832.9987095 & 783.9164460 & 817.6301115 \\
\hline$C_{T}^{W}(\$ / h)$ & & & & 144.7990782 & & 453.0677743 \\
\hline$C_{T}^{P V}(\$ / \mathrm{h})$ & & & & 309.4797989 & 382.2292034 & \\
\hline$f_{o}(\$ / h)$ & & & 964.2232199 & 927.1649129 & 889.8329526 & 889.1206976 \\
\hline
\end{tabular}

\section{Conclusions}

In this study, a novel proposed EO method has been successfully applied to solve single and multi-objective OPF with integrated wind turbines and solar PV generators. Its performance and effectiveness were evaluated on four power system, namely: IEEE 30-bus system, wind integrated IEEE 30-bus system, solar PV integrated IEEE 30-bus system, and hybrid wind and solar PV integrated IEEE 30-bus system. Realistic models for the wind turbines and solar PV systems have been proposed and 
thus real power outputs of wind turbines and solar PV power plants have been accurately forecasted. Therefore, a correct and efficient decision can be taken for inclusion the wind turbines and solar PV power plants in the proper locations. The simulation and statistical results indicate and approve that the EO [34] method outperforms other optimization techniques, namely: TLBO [46], MPSO [45], MFO [47], AGPSO1 [45], and TACPSO [45]. Our research has highlighted the importance of the proper locations of the renewable energy resources on improving the objective functions of OPF problem. Furthermore, adding wind turbines and solar PV play an integral role in enhancing the performance of the standard IEEE 30-bus system. For example, they significantly reduce the fuel cost and emission of the conventional power generators, as well as minimize real power loss and voltage deviation.

Author Contributions: Both authors have made equal contributions to this work. All authors have read and agreed to the published version of the manuscript.

Funding: This research received no external funding.

Conflicts of Interest: The authors declare no conflict of interest.

\section{Abbreviations}

$\begin{array}{ll}\text { OPF } & \text { Optimal power flow } \\ \text { NLP } & \text { Continuous nonlinear programming } \\ \text { PCIP } & \text { Predictor-corrector interior point algorithm } \\ \text { PSO } & \text { Particle swarm optimization } \\ \text { QP } & \text { Quadratic programming } \\ \text { SQP } & \text { Sequential quadratic programming } \\ \text { MILP } & \text { Mixed-integer linear programming } \\ \text { TLBO } & \text { Teaching-learning-based optimization } \\ \text { GSA } & \text { Gravitational search algorithm } \\ \text { DE } & \text { Differential evolution algorithm } \\ \text { MTLBO } & \text { Modified teaching learning-based optimization algorithm } \\ \text { MABC } & \text { Fuzzy-based modified bee colony } \\ \text { BSO } & \text { Brain storming optimization } \\ \text { GWO } & \text { Grey wolf optimization algorithm } \\ \text { EO } & \text { Equilibrium optimizer algorithm } \\ \text { FACTS } & \text { Flexible alternating current transmission system }\end{array}$

\section{References}

1. Roy, R.; Jadhav, H. Optimal power flow solution of power system incorporating stochastic wind power using Gbest guided artificial bee colony algorithm. Int. J. Electr. Power Energy Syst. 2015, 64, 562-578. [CrossRef]

2. Shi, L.; Wang, C.; Yao, L.; Ni, Y.; Bazargan, M. Optimal power flow solution incorporating wind power. IEEE Syst. J. 2011, 6, 233-241. [CrossRef]

3. Biswas, P.P.; Suganthan, P.N.; Mallipeddi, R.; Amaratunga, G.A. Optimal reactive power dispatch with uncertainties in load demand and renewable energy sources adopting scenario-based approach. Appl. Soft Comput. 2019, 75, 616-632. [CrossRef]

4. Biswas, P.P.; Suganthan, P.; Amaratunga, G.A. Optimal power flow solutions incorporating stochastic wind and solar power. Energy Convers. Manag. 2017, 148, 1194-1207. [CrossRef]

5. Dommel, H.; Tinney, W. Optimal power flow solutions. IEEE Trans. Power Appar. Syst. 1968, PAS-87, 1866-1876. [CrossRef]

6. Jabr, R.A. Optimal power flow using an extended conic quadratic formulation. IEEE Trans. Power Syst. 2008, 23, 1000-1008. [CrossRef]

7. Lin, W.M.; Huang, C.H.; Zhan, T.S. A hybrid current-power optimal power flow technique. IEEE Trans. Power Syst. 2008, 23, 177-185. [CrossRef]

8. Glavitsch, H.; Spoerry, M. Quadratic loss formula for reactive dispatch. IEEE Trans. Power Appar. Syst. 1983, PAS-102, 3850-3858. [CrossRef] 
9. Burchett, R.; Happ, H.; Wirgau, K. Large scale optimal power flow. IEEE Trans. Power Appar. Syst. 1982, PAS-101, 3722-3732. [CrossRef]

10. Lobato, E.; Rouco, L.; Navarrete, M.; Casanova, R.; Lopez, G. An LP-based optimal power flow for transmission losses and generator reactive margins minimization. In Proceedings of the 2001 IEEE Porto Power Tech Proceedings (Cat. No. 01EX502), Porto, Portugal, 10-13 September 2001; Volume 3, 5p.

11. Duman, S.; Güvenç, U.; Sönmez, Y.; Yörükeren, N. Optimal power flow using gravitational search algorithm. Energy Convers. Manag. 2012, 59, 86-95. [CrossRef]

12. El Ela, A.A.; Abido, M.; Spea, S. Optimal power flow using differential evolution algorithm. Electr. Power Syst. Res. 2010, 80, 878-885. [CrossRef]

13. Bouchekara, H. Optimal power flow using black-hole-based optimization approach. Appl. Soft Comput. 2014, 24, 879-888. [CrossRef]

14. Mohamed, A.A.A.; Mohamed, Y.S.; El-Gaafary, A.A.; Hemeida, A.M. Optimal power flow using moth swarm algorithm. Electr. Power Syst. Res. 2017, 142, 190-206. [CrossRef]

15. Hazra, J.; Sinha, A. A multi-objective optimal power flow using particle swarm optimization. Eur. Trans. Electr. Power 2011, 21, 1028-1045. [CrossRef]

16. Bhattacharya, A.; Roy, P. Solution of multi-objective optimal power flow using gravitational search algorithm. IET Gener. Transm. Distrib. 2012, 6, 751-763. [CrossRef]

17. Shabanpour-Haghighi, A.; Seifi, A.R.; Niknam, T. A modified teaching-learning based optimization for multi-objective optimal power flow problem. Energy Convers. Manag. 2014, 77, 597-607. [CrossRef]

18. Kumar, S.; Chaturvedi, D. Optimal power flow solution using fuzzy evolutionary and swarm optimization. Int. J. Electr. Power Energy Syst. 2013, 47, 416-423. [CrossRef]

19. Khorsandi, A.; Hosseinian, S.; Ghazanfari, A. Modified artificial bee colony algorithm based on fuzzy multi-objective technique for optimal power flow problem. Electr. Power Syst. Res. 2013, 95, 206-213. [CrossRef]

20. Ghasemi, M.; Ghavidel, S.; Ghanbarian, M.M.; Gharibzadeh, M.; Vahed, A.A. Multi-objective optimal power flow considering the cost, emission, voltage deviation and power losses using multi-objective modified imperialist competitive algorithm. Energy 2014, 78, 276-289. [CrossRef]

21. Narimani, M.R.; Azizipanah-Abarghooee, R.; Zoghdar-Moghadam-Shahrekohne, B.; Gholami, K. A novel approach to multi-objective optimal power flow by a new hybrid optimization algorithm considering generator constraints and multi-fuel type. Energy 2013, 49, 119-136. [CrossRef]

22. Ghasemi, M.; Ghavidel, S.; Akbari, E.; Vahed, A.A. Solving non-linear, non-smooth and non-convex optimal power flow problems using chaotic invasive weed optimization algorithms based on chaos. Energy 2014, 73, 340-353. [CrossRef]

23. Krishnanand, K.; Hasani, S.M.F.; Panigrahi, B.K.; Panda, S.K. Optimal power flow solution using self-evolving brain-storming inclusive teaching-learning-Based algorithm. In Proceedings of the International Conference in Swarm Intelligence, Harbin, China, 12-15 June 2013; Springer: Berlin/Heidelberg, Germany, 2013.

24. Sivasubramani, S.; Swarup, K. Sequential quadratic programming based differential evolution algorithm for optimal power flow problem. IET Gener. Transm. Distrib. 2011, 5, 1149-1154. [CrossRef]

25. Reddy, S.S. Optimal power flow with renewable energy resources including storage. Electr. Eng. 2017, 99, 685-695. [CrossRef]

26. Shilaja, C.; Arunprasath, T. Optimal power flow using Moth Swarm Algorithm with Gravitational Search Algorithm considering wind power. Future Gener. Comput. Syst. 2019, 98, 708-715.

27. Aien, M.; Fotuhi-Firuzabad, M.; Rashidinejad, M. Probabilistic optimal power flow in correlated hybrid wind-photovoltaic power systems. IEEE Trans. Smart Grid 2014, 5, 130-138. [CrossRef]

28. Aien, M.; Rashidinejad, M.; Firuz-Abad, M.F. Probabilistic optimal power flow in correlated hybrid wind-PV power systems: A review and a new approach. Renew. Sustain. Energy Rev. 2015, 41, 1437-1446. [CrossRef]

29. Liang, R.H.; Tsai, S.R.; Chen, Y.T.; Tseng, W.T. Optimal power flow by a fuzzy based hybrid particle swarm optimization approach. Electr. Power Syst. Res. 2011, 81, 1466-1474. [CrossRef]

30. Shilaja, C.; Ravi, K. Optimal power flow using hybrid DA-APSO algorithm in renewable energy resources. Energy Procedia 2017, 117, 1085-1092. [CrossRef] 
31. Das, T.; Roy, R.; Mandal, K.K.; Mondal, S.; Mondal, S.; Hait, P.; Das, M.K. Optimal Reactive Power Dispatch Incorporating Solar Power Using Jaya Algorithm. In Computational Advancement in Communication Circuits and Systems; Springer: Berlin/Heidelberg, Germany, 2020; pp. 37-48.

32. Chen, M.R.; Zeng, G.Q.; Lu, K.D. Constrained multi-objective population extremal optimization based economic-emission dispatch incorporating renewable energy resources. Renew. Energy 2019, 143, 277-294. [CrossRef]

33. Rambabu, M.; Nagesh Kumar, G.; Sivanagaraju, S. Optimal Power Flow of Integrated Renewable Energy System using a Thyristor Controlled Series Compensator and a Grey-Wolf Algorithm. Energies 2019, 12, 2215. [CrossRef]

34. Faramarzi, A.; Heidarinejad, M.; Stephens, B.; Mirjalili, S. Equilibrium optimizer: A novel optimization algorithm. Knowl. Based Syst. 2019, 195, 105190. [CrossRef]

35. Biswas, P.P.; Suganthan, P.N.; Mallipeddi, R.; Amaratunga, G.A. Optimal power flow solutions using differential evolution algorithm integrated with effective constraint handling techniques. Eng. Appl. Artif. Intell. 2018, 68, 81-100. [CrossRef]

36. Shaheen, A.M.; El-Sehiemy, R.A.; Farrag, S.M. Solving multi-objective optimal power flow problem via forced initialised differential evolution algorithm. IET Gener. Transm. Distrib. 2016, 10, 1634-1647. [CrossRef]

37. Panda, A.; Tripathy, M. Security constrained optimal power flow solution of wind-thermal generation system using modified bacteria foraging algorithm. Energy 2015, 93, 816-827. [CrossRef]

38. Shargh, S.; Mohammadi-Ivatloo, B.; Seyedi, H.; Abapour, M. Probabilistic multi-objective optimal power flow considering correlated wind power and load uncertainties. Renew. Energy 2016, 94, 10-21. [CrossRef]

39. Biswas, P.P.; Suganthan, P.N.; Qu, B.Y.; Amaratunga, G.A. Multiobjective economic-environmental power dispatch with stochastic wind-solar-small hydro power. Energy 2018, 150, 1039-1057. [CrossRef]

40. Hu, F.; Hughes, K.J.; Ma, L.; Pourkashanian, M. Combined economic and emission dispatch considering conventional and wind power generating units. Int. Trans. Electr. Energy Syst. 2017, 27, e2424. [CrossRef]

41. Hu, F.; Hughes, K.J.; Ingham, D.B.; Ma, L.; Pourkashanian, M. Dynamic economic and emission dispatch model considering wind power under Energy Market Reform: A case study. Int. J. Electr. Power Energy Syst. 2019, 110, 184-196. [CrossRef]

42. Taha, I.B.; Elattar, E.E. Optimal reactive power resources sizing for power system operations enhancement based on improved grey wolf optimiser. IET Gener. Transm. Distrib. 2018, 12, 3421-3434. [CrossRef]

43. Alsac, O.; Stott, B. Optimal load flow with steady-state security. IEEE Trans. Power Appar. Syst. 1974, PAS-93, 745-751. [CrossRef]

44. Zimmerman, R.D.; Murillo-Sánchez, C.E.; Gan, D. MATPOWER: A MATLAB power system simulation package. Manual Power Syst. Eng. Res. Center Ithaca NY 1997, 1, 8-38.

45. Mirjalili, S.; Lewis, A.; Sadiq, A.S. Autonomous particles groups for particle swarm optimization. Arab. J. Sci. Eng. 2014, 39, 4683-4697. [CrossRef]

46. Rao, R.V.; Savsani, V.J.; Vakharia, D. Teaching-Learning-based optimization: An optimization method for continuous non-linear large scale problems. Inf. Sci. 2012, 183, 1-15. [CrossRef]

47. Mirjalili, S. Moth-flame optimization algorithm: A novel nature-inspired heuristic paradigm. Knowl. Based Syst. 2015, 89, 228-249. [CrossRef]

Publisher's Note: MDPI stays neutral with regard to jurisdictional claims in published maps and institutional affiliations.

(C) 2020 by the authors. Licensee MDPI, Basel, Switzerland. This article is an open access article distributed under the terms and conditions of the Creative Commons Attribution (CC BY) license (http:/ / creativecommons.org/licenses/by/4.0/). 